University of Warwick institutional repository: http://go.warwick.ac.uk/wrap This paper is made available online in accordance with publisher policies. Please scroll down to view the document itself. Please refer to the repository record for this item and our policy information available from the repository home page for further information.

To see the final version of this paper please visit the publisher's website. Access to the published version may require a subscription.

Author(s): Brown, Gordon D.A.; Gardner, Jonathan; Oswald, Andrew J.; Qian, Jing

Article Title: Does Wage Rank Affect Employees' Well-being?

Year of publication: 2008

Link to published version: http://dx.doi.org/10.1111/j.1468-

232X.2008.00525.x

Publisher statement: The definitive version is available at www.blackwell-synergy.com 


\title{
Does Wage Rank Affect Employees' Well-being?
}

\author{
September 2007
}

Forthcoming in Industrial Relations

\author{
Gordon D.A. Brown \\ Department of Psychology, University of Warwick, Coventry, CV4 7AL, United \\ Kingdom. Tel: +44 (0) 2476524672 \\ Jonathan Gardner \\ Research \& Development, Watson Wyatt Worldwide, Watson House, London Road \\ Reigate, Surrey, RH2 9PQ, United Kingdom. Tel: +44 (0) 1737274097 \\ Andrew J. Oswald \\ Department of Economics, University of Warwick, Coventry, CV4 7AL, United \\ Kingdom. Tel: +44 (0) 2476523032
}

\section{Jing Qian}

ABC Research Group, Max Planck Institute for Human Development, Lentzeallee 94,

14195 Berlin, Germany. Tel: +49 (0) 3082406692

\begin{abstract}
We are grateful to three anonymous referees for extremely valuable suggestions. This research was supported by grants 88/S15050 from BBSRC (UK) and grants R000239002 and R000239351 from ESRC (UK). Oswald's work was supported by an ESRC Professorial Fellowship. The first version of this paper was written in 2002. Opinions in this article are those of individual authors only; they do not necessarily reflect views or policies of Watson Wyatt. For helpful suggestions, we thank Dick Easterlin, Richard Freeman, Carol Graham, Larry Katz, Tatiana Kornienko, George Lowenstein, Erzo Luttmer, Karl Schag, and Frank Vella. We also thank participants in presentations at a 2003 Brookings Institution conference; Gary Becker's evening seminar at the University of Chicago; the 2005 American Economic Association Meeting in Washington DC; and research seminars at the universities of Edinburgh, Essex, the European University Institute (Florence), Harvard, Oxford, Paris, Warwick, and York.
\end{abstract}


Does Wage Rank Affect Employees' Well-being?

\begin{abstract}
How do workers make wage comparisons? Both an experimental study and an analysis of 16,000 British employees are reported. Satisfaction and well-being levels are shown to depend on more than simple relative pay. They depend upon the ordinal rank of an individual's wage within a comparison group. 'Rank' itself thus seems to matter to human beings. Moreover, consistent with psychological theory, quits in a workplace are correlated with pay distribution skewness.
\end{abstract}

JEL codes: J3; J28; I31.

Key words: Range-frequency theory; relative wages; rank; job satisfaction; well-being; happiness; comparison income; pay differentials. 
"Negatively skewed distributions of events ... are the most conducive to happiness... Thus, the contextual theory of happiness differs from the theory of expected utility so popular in economics and decision analysis." Allen Parducci (1995, p. 102)

\section{Introduction}

This paper argues that human well-being depends in a particular way upon comparisons with others. An individual is influenced not just by relative income but by the rank-ordered position of his or her wage within a comparison set (for example, whether the individual is the fourth most highly paid person in the organization, or the forty-fourth most highly paid). Human beings, in other words, value ordinal position per se.

Economists' formal models rarely consider a role for income rank in utility functions (although the idea is discussed in Layard 1980 and Frank 1985, and Hopkins and Kornienko 2004 consider related ideas). Nevertheless, there are natural intuitive arguments. First, if preferences are strongly shaped by evolutionary biology, it might be expected that rank would be of importance to humans. For a female who is searching for a mate, for example, the desirability of a male depends on his ordered position -- where the ordering is over resources that will be available to offspring -within a hierarchy of possible sexual partners. Second, casual observation of the world suggests that human beings are deeply interested in rankings -- over sports outcomes, over incomes as described in newspaper 'rich lists', over even lists of economists (as in repec.org) -- to an extent that seems hard to understand if the sole purpose of rankings is the provision of information. Third, if people care about ordinal standing rather than absolute income, this would be one way to rationalize the famous observation of Richard Easterlin (1974) that reported happiness does not rise as a nation becomes wealthier. Moreover, as discussed later, concern about rank is not synonymous with concern over relative wages (as defined, say, by the individual's income divided by mean group income). Hopkins and Kornienko (2004) and Layard $(1980,2005)$ point out that behavior and socially optimal allocations are not identical under these two different assumptions.

This paper draws upon a model known as Range Frequency Theory (Parducci, 1965; 1995). Although unfamiliar to economists and most industrial relations researchers, this model leads to the theoretical prediction that well-being is shaped by 
the ordinal position of a person's wage within a comparison set of others' wage levels. As we try to show later, the theory fits the patterns observed in data.

Textbook economics assumes that a person's utility varies positively with their absolute pay level and negatively with the number of hours worked. Workers like income and dislike effort. This can be expressed as a utility function:

$$
\mathrm{u}=\mathrm{u}\left(\mathrm{w}_{\mathrm{abs}}, h, i, j\right)
$$

where $\mathrm{u}$ is the utility or well-being gained from working, $\mathrm{w}_{\mathrm{abs}}$ is the absolute level of wage income, $h$ is hours of work, and the additional parameters are characteristics of the individual worker $(i)$ and the job $(j)$. Much research within psychology has also focussed on absolute, rather than relative, pay levels.

Nevertheless, some researchers have attempted to capture the intuition that relative wages may be an important determinant of utility. For example, Hamermesh (1975) argued that utility might be derived from obtaining wages greater than the average wage of an appropriate comparison group. Rees (1993) discussed a number of informal arguments for the importance of relative wages in determining perceived fairness and wage satisfaction. Clark and Oswald (1996), using data collected from 5,000 UK workers, found evidence consistent with the idea that utility depends partly on income relative to some reference or comparison income level. Groot and Van den Brink (1999) concluded that pay satisfaction is determined by relative rather than absolute wages. Using panel data, Clark (2003) showed that the impact of unemployment on well-being is subject to social-comparison effects. Blanchflower and Oswald (2004) and Luttmer (2005) argued, using somewhat different methods, that Americans are happier in areas where their neighbors are poorer. More generally, attitudes are known to be correlated with well-being (for example, Di Tella \& MacCulloch 2005). A number of other studies have emphasized the importance of some kind of reference group in determining pay and job satisfaction. ${ }^{\mathrm{i}}$ This way of thinking leads to an expression for the utility function such as:

$$
\mathrm{u}=\mathrm{u}\left(\mathrm{w}_{\mathrm{abs}}, \mathrm{w}_{\text {mean }}, h, i, j\right)
$$

where the additional term, $\mathrm{w}_{\text {mean, }}$ is a reference wage that is taken to be negatively associated with utility. Comparison effects of the type embodied in Equation 2 have 
been a concern of the social sciences outside economics, most notably in studies of relative deprivation (Runciman, 1966) and in epidemiological research (Marmot, 1994).

More recently, it has been emphasised that disutility may stem from discrepancies between the current state and an aspiration level (e.g. Gilboa \& Schmeidler, 2001; Stutzer, 2004). A related idea, that losses and gains are assessed not in absolute terms but in terms of the change from a reference point (such as the current state), has received wide currency in prospect theory (Kahneman \& Tversky, 1979; see also Munro \& Sugden, 2003). The theoretical implications for economic models of a concern for relative income have also been discussed. ${ }^{\text {ii }}$ However, only a little research has focussed on how people actually determine the reference group (e.g. Bygren, 2004; Law \& Wong, 1998).

In principle, more than one reference point may be used to determine worker satisfaction (cf. Kahneman, 1992). Then, in some form, income 'rank' effects can occur. ${ }^{\mathrm{iii}} \mathrm{A}$ concern for rank-based status might have neurobiological underpinnings or serve an evolutionarily useful informational role (Zizzo, 2002; Samuelson, 2004). It should be mentioned in passing that our paper's attempt to employ a psychologically motivated model of rank-dependent satisfaction is consistent with a body of medical research that has been concerned -- in part by following longitudinally a Whitehall sample of British civil servants -- with the effects of position and inequality upon health (e.g. Deaton, 2001; Marmot, 1994; Marmot \& Bobak, 2000).

The issue of rank-dependence has received little direct attention in the context of employee satisfaction, but some empirical findings have been consistent with a multiple-reference perspective. Ordonez, Connolly and Coughlan (2000) presented evidence that the judged fairness of a salary level was determined by comparisons to more than one referent (cf. also Highhouse, Brooks-Laber, Lin, \& Spitzmueller, 2003; Seidl, Traub, \& Morone, 2003). Mellers (1982) examined how individuals chose to achieve fairness when they were given a sum of money to allocate between hypothetical members of a university faculty. The results demonstrated that the distribution of merit was relevant. Mellers (1986) showed that a concern for rank helped account for judgments of "fair" allocations of costs (taxes). Ratings of happiness also seem to be determined by the skewness of the distribution of events (Smith, Diener, \& Wedell, 1989), and by the shape of nations' income distributions (Hagerty, 2000). Yet, within the economics literature, little attention is paid to the 
distribution of gains, losses, probabilities, or risks on the treatment of any individual loss, gain, or probability (although see e.g. Cox \& Oaxaca, 1989; Lopes, 1987).

We now lay out an approach based on Range Frequency Theory, which is due to Allen Parducci of the University of California (RFT: Parducci, 1965, 1995). Later we relate RFT to models of inequality aversion (Fehr \& Schmidt, 1999).

While economists' modelling is traditionally individualistic, Parducci's argument is that context matters, and in a fundamental way. Contextual effects on judgment have been investigated empirically (for example, Parducci, 1965, 1995). Models of context have begun to be applied in economic and consumer psychology. ${ }^{\text {iv }}$ In a different domain, Oswald and Powdthavee (2007) study how obesity relative to others' weight may affect utility.

The possibility that judgments, for example of a wage, are made relative to a single reference point is reminiscent of Helson's (1964) Adaptation Level Theory. This theory assumes that judgments about simple perceptual magnitudes -- such as weights, loudnesses, or brightnesses -- are made in relation to the weighted mean of contextual stimuli. While "reference point" models often assume that judgments are made in relation to a mean level of some kind, there is evidence that human beings are influenced by the endpoints and variance of a distribution (see Volkmann, 1951; Janiszewski \& Lichtenstein, 1999).

A central idea in Range Frequency Theory is that the ordinal position of an item within a ranking is important. The conceptual issues are illustrated in Figure 1. Here the items can be thought of as magnitudes along any continuum (such as prices, wages, probabilities, weights, line lengths). Consider point $\mathrm{X}$ in Figure 1. How will its magnitude be judged? Point $\mathrm{X}$ has the same arithmetical value in distribution $\mathrm{A}$ as in distribution $\mathrm{B}$. In both cases, $\mathrm{X}$ is the same distance from the mean. It is also the same distance from the mid-point, and from the end points. Simple reference theory, such as that underlying the idea that a worker's utility depends on the ratio of pay to mean pay, then makes a clear prediction. It suggests that people should be indifferent between point $\mathrm{X}$ in distribution $\mathrm{A}$ and in distribution $\mathrm{B}$. Yet it has been confirmed by empirical observation in a number of settings that human beings tend to judge the magnitude of $\mathrm{X}$ as lower in distribution $\mathrm{A}$ (where $\mathrm{X}$ is the second lowest stimulus rather than the fifth lowest one). Analogous considerations apply, in reverse, for a stimulus like that represented by point Y (see Parducci, 1995, for a review). 
Range Frequency Theory was initially designed for uni-dimensional stimuli such as weights, line lengths, or tones. The conceptual model developed by Parducci $(1965,1995)$ rests on the idea that feelings triggered by a stimulus are determined by both its position within a range and its ordinal position. This can be expressed as follows.

Assume an ordered set of $n$ items:

$\left\{x_{1}, x_{2}, \ldots \ldots x_{i}, \ldots . x_{n}\right\}$

Then, if $M_{i}$ is the subjective psychological magnitude of $x_{i}$, that magnitude is taken to be given by the simple convex combination:

$M_{i}=w R_{i}+(1-w) F_{i}$

where $w$ is a weight and $R_{i}$ is the range value of stimulus $i$ :

$R_{i}=\frac{x_{i}-x_{1}}{x_{n}-x_{1}}$

and $F_{i}$ is the frequency value (in the language of Parducci), or, perhaps in more natural terminology, the ranked ordinal position of $S_{I}$, within the ordered set:

$F_{i}=\frac{i-1}{n-1}$

In other words, for a worker who is the $20^{\text {th }}$ best-paid employee out of the 101 people in her workplace, $F_{i}$ will be 0.19 .

The subjective magnitude of a stimulus is thus assumed by Range Frequency Theory to be given by a weighted average of R and F. It is a convex combination of (a) the position of the stimulus along a line made up of the lowest and highest points in the set and (b) the rank ordered position of the stimulus with regard to the other contextual stimuli. To get consistency of units, $M_{i}$ is constrained to values between 0 and 1. If subjective magnitude estimates are given on, e.g., a 1 to 7 scale, then an appropriate linear transformation into the unit interval is done. Here $w$ is a weighting 
parameter. In physical judgments in the laboratory, this is often estimated at approximately 0.5 . We might hypothesize that an employee's feelings of satisfaction will be governed equivalently within a set of comparison wages (see Seidl et al., 2003, for a related hypothesis).

Various testable ideas can be viewed as being nested within the following utility equation:

$\mathrm{u}=\mathrm{u}\left(\mathrm{w}_{\mathrm{abs}}, \mathrm{w}_{\text {mean }}, \mathrm{w}_{\text {rank }}, \mathrm{w}_{\text {range }}, h, i, j\right)$

where $w_{\text {rank }}$ and $w_{\text {range }}$ are, respectively, defined for wages as in Equations 4 and 5. In this formulation, $\mathrm{w}_{\mathrm{abs}}$ and $\mathrm{w}_{\text {mean }}$ remain in the model. If pure RFT were to govern satisfaction, the variables $\mathrm{w}_{\mathrm{abs}}$ and $\mathrm{w}_{\text {mean }}$ would have no influence on $\mathrm{u}$.

Smith, Diener, and Wedell (1989), in a laboratory-based study, found that RFT gave a fairly good account of both overall happiness ratings, and individual event ratings, when the happiness-giving events were drawn from positively and negatively skewed distributions. Hagerty (2000) concluded that, as predicted by RFT, mean happiness ratings were greater in communities where the income distributions were less positively skewed. He found that this effect held both within and across countries. In addition, Mellers $(1982,1986)$ concluded that RFT could give a coherent account of the judged fairness of wage distributions. Finally, Highhouse et al. (2003) found that salary expectations conformed to RFT principles, and Seidl et al. (2003) used RFT to model categorisation of incomes in a hypothetical currency. Yet this analytical approach has made almost no impression on the discipline of economics.

The next three sections of the paper test the idea that RFT can be used to understand workers' wellbeing using complementary methods: a laboratory-based study (Section II); analysis of self-rated workplace well-being using large-scale surveys (Section III); an analysis of quits (Section IV).

\section{Investigation 1: A Small Experiment}

The paper's first test, Investigation 1, uses wage-satisfaction data from a laboratory setting.

We asked undergraduates -- a relatively homogeneous group -- to rate how satisfied they would be with wages that they might be offered for their first job after 
college. None was familiar with RFT. The key experimental manipulation was of the distribution of other hypothetical wages said to be offered to their classmates for similar jobs.

In this way, the subjects expressed feelings about each potential wage in the context of a set of other wages. Six different wage distributions were used. There were 11 hypothetical wages in each distribution. Each participant was required to evaluate how satisfied they would be with each pay level.

The wage distributions are illustrated in Figure 2, while the actual wages used are listed in Table 1. The first two distributions (A and B, which are here denoted unimodal and bimodal, respectively) are designed to test for rank-dependence, and follow the logic illustrated in Figure 1. Three wages are common to both distributions (excluding the lowest and highest wages); these are labelled A1 - A3 and B1 - B3. Points A1 and B1 in Figure 2 are the same distance from the mean. They are also the same proportion up the range from lowest to highest. Thus, according to a simple reference-wage view, $\mathrm{A} 1$ and $\mathrm{B} 1$ should be given the same ratings. So should $\mathrm{A} 2$ and B2. So too should A3 and B3. According to the hypothesis of rank-dependence, in contrast, point A1 will be rated as less satisfying than will B1 (because A1 is the second lowest wage, while B2 is the 5th lowest). The reverse will be true for A3 and B3. Points $\mathrm{A} 2$ and $\mathrm{B} 2$ ought to receive the same rating in both cases. By design, therefore, distributions $\mathrm{A}$ and $\mathrm{B}$ should provide a clean test -- of a very simple kind -for the existence of rank-dependence.

The next two distributions in Figure 2, namely $\mathrm{C}$ (positive skew) and $\mathrm{D}$ (negative skew), test the explanatory ability of the model when the distribution is negatively skewed. These distributions, $\mathrm{C}$ and $\mathrm{D}$, have two points in common. The fifth-highest wage in the negatively skewed distribution is the same as the secondhighest wage in the positively skewed distribution. The second-lowest wage in the negatively skewed distribution is the same as the fifth-lowest wage in the positively skewed distribution. However, the distributions have different means. Hence any difference in satisfaction ratings is theoretically ambiguous, because the relevant wages differ between the distributions in both ranked position and in distance from the mean. The final two distributions, E (low range) and $\mathrm{F}$ (high range), allow a test of the idea that position up the range is important in determining wage satisfaction. The critical sixth-lowest wage is the same in both distributions, and represents both the mean and the median in each distribution. But in the low-range condition the 
critical wage is $60 \%$ up the range from lowest to highest wage, while it is $40 \%$ up the range in the high range condition. A difference in the satisfaction from this critical wage ought then to be unambiguous evidence for a 'range' effect on well-being.

Twenty-four laboratory subjects were tested. The results turned out to be so uniform that it was felt unnecessary to extend the results to a larger sample. All subjects were first-year psychology students ( 17 women and 7 men, mean age $=19.0$ years). They participated for course credit.

Six rating scales and 66 coloured labels were used. Rating scales were $36 \mathrm{~cm}$ long by $4 \mathrm{~cm}$ wide strips of paper. On these, a 7-point scale (34 cm long) was drawn, in the centre of the strip. Each scale had seven equally spaced markers indicated (labelled 1-7). No other written information was present on the scale. Small labels were constructed to represent the wages to be rated; annual wages in pounds sterling were printed in a rectangular box on the labels; the top of each label was made in the shape of a pointer. Labels were presented to subjects in an unordered fashion. By placing the label's pointer at the appropriate place on the scale, this could be used to indicate the satisfaction rating for the hypothetical wage.

The experimental design was within-subjects, with six levels of annual wage distribution (as illustrated in Figure 2 and described above). Table 1 lists the wage values. A 6 x 6 Latin square design was used.

Participants were tested individually and given written instructions. The task was to state how satisfied they would be with each of 11 hypothetical annual starting salaries. This was, by design, within the context of the other 10 salaries offered to classmates. They were asked to imagine that these were starting salaries offered to similar graduates entering a similar occupation. Subjects were then required to assess the eleven salaries using a 7-point rating scale, with 1 being "least satisfied," and 7 to "most satisfied". After they finished their evaluations, the experimenter measured the chosen positions of the labels. A new rating scale was then provided to participants with a different set of labels for the next distribution.

The results of this simple experiment are shown in Figure 3. We analysed the data in three ways. First, we examined the overall ability of the RFT model to fit the data. Second, we compared the satisfaction levels assigned to the wages that were common to different distributions. Finally, we embedded RFT within a more general framework, and compared its performance with other extant models. 
Our analysis started with the RFT model of Equation 3. We computed the best-fitting parameter estimates. This is akin to fitting standard OLS of satisfaction responses on rank and range as covariates, but where the parameters are constrained to be $w$ and $1-w$. There is just one free parameter: the parameter $w$ that specifies the weighting given to the ranking dimension relative to the range dimension. We adopted the conservative procedure of holding $w$ constant for all six distributions; there was therefore a single value of one parameter to estimate for all 66 data points (11 in each of 6 distributions). The fit, from the pooled estimates, is shown as a solid line in each of the three figures (Figure $3 \mathrm{a}$ to $3 \mathrm{c}$ ). A good match between model and data was also obtained when results from individual subjects were modeled, providing reassurance that the overall fit did not reflect averaging artefacts or the chance selection of a few idiosyncratic participants. The overall $\mathrm{R}^{2}$ value obtained is .998 , and the estimate of $w$ is 0.36 .

Model-comparison statistics confirmed the importance of both range and rank. We compared the goodness of fit of the model with and without the $w$ parameter included (Borowiak, 1989). A restricted model, in which only range influences ratings, produced a significantly less good fit: $\left(\chi^{2}(1)=241.9, \underline{p}<.001\right)$. So too did a restricted model in which only ranked position influences satisfaction ratings: $\left(\chi^{2}(1)=169.1\right.$, $\mathrm{p}<.001)$.

This method assumes that the psychological magnitudes, prior to assessment, are a linear function of actual wage amount. We explored the possibility that a logarithmic or power-law transformation of the wage variables might instead improve the fit of the model. In neither case, however, did this lead to a significant increase in the explained variance.

We find other evidence for rank-dependence. The differences in the mean rating of common points in comparative conditions were analysed using ANOVA. There are three critical wage stimuli for the unimodal and bimodal distributions. They are the points labelled A1 through B3 in Figure 2. These points permit a test of the effect of rank when proportion up the range, and distance from the mean, are both held constant. An initial two-way ANOVA on the ratings given to the common points found, as expected, a main effect of point within distribution $(\underline{F}(2,46)=809.17$; $\underline{\mathrm{p}}<.001)$; no main effect of distribution $(\underline{\mathrm{F}}(1,23)=0.60)$; and an interaction between them $(\underline{F}(2,46)=124.68 ; \underline{p}<.001)$. Tests confirmed that -- at high levels of significance - 
- the wage of $£ 20.0 \mathrm{~K}$ was rated as less satisfying when it was the second lowest wage than when it was the fifth lowest wage. Moreover, the wage of $£ 25.6 \mathrm{~K}$ was rated as more satisfying when it was the second highest wage than when it was the fifth highest.

In the comparison of positive skew and negative skew, $£ 19.5 \mathrm{~K}$ and $£ 26.1 \mathrm{~K}$ were the common salaries in both cases. The range difference between these points and the endpoints was the same in both conditions, but the positions in the rank orders were different. The salary $£ 19.5 \mathrm{~K}$ is the fifth lowest wage in the positive-skew condition but the second lowest in the negatively skewed condition. Conversely, $£ 26.1 \mathrm{~K}$ ranks second highest in the positive-skew condition but fifth highest in the negative-skew condition. Because the means of the two distributions were not the same, the distances of the common points to the mean were also different. A $2 \times 2$ (common points X condition) ANOVA was used, and found the expected main effects of condition (ratings were higher in the positively skewed condition: $\underline{F}(1,23)=159.99$; $\mathrm{p}<.001$ ) and point (ratings were higher for wages in the positive condition: $\underline{\mathrm{F}}(1,23)=1860.02 ; \underline{\mathrm{p}}<.001)$. The interaction was not significant $(\underline{\mathrm{F}}(1,23)=1.0)$. Satisfaction levels were consistently higher, at all reasonable confidence levels, in the positively skewed than in the negatively skewed case. This was true for both the lower wage and the higher wage. These results are strongly consistent with RFT.

The single common point for the high-range and low-range conditions can be examined in a similar way. Salary $£ 22.8$, which was the mean and the median of the distribution, has the same ranked position in both distributions, but different range values. A paired-sample t-test was used, and the analysis revealed, consistent with the predictions of RFT, that the effect of range was significant: $\underline{t}(23)=2.435, \underline{p}<.05$ (two tailed). These results are consistent with those of Seidl et al. (2003) who, in a study that came to our notice after the present experiments were completed, demonstrated that RFT gave a good account of experimentally-obtained categorizations of incomes in a hypothetical currency. The results are also consistent with studies that have paid subjects according to different distributions, which have shown that subjects receiving a negatively skewed distribution of rewards report greater satisfaction (Parducci 1968, $1995)$.

We should note a possible limitation of the experiment. The laboratory-based nature of the design may lead subjects to perform in a particular way. However, this difficulty is tackled in the next section of the paper where a real-world setting is 
employed. We also should note that the pay information was simultaneously and visually available to subjects, perhaps increasing the likelihood that it would be processed in the same way as other physical stimuli. A further experiment, not reported here, addressed this issue by presenting wages for sequential evaluation, and RFT fitted the data.

Compared to RFT theory, how well might other models do? It has been argued that the notion of fairness needs to be incorporated into conceptions of utility. ${ }^{\mathrm{v}}$ If pay satisfaction depends on perceived unfairness, then models of inequity perception could be applied to the present case. Given that RFT has already been shown to provide a good fit to fair-salary increases and tax assignments (Mellers, 1982, 1986), the present data provide an opportunity to examine the different predictions of RFT and economic models of inequity as applied to wage satisfaction.

Can economic models mirror the predictions of the psychologically-motivated RFT? Fehr and Schmidt (2001) set out a model of inequity aversion. In intuitive terms, the idea is that utility may depend on (a) an absolute level of resource $x_{i}$, (b) the total weight of resources above $x_{i}$, and (c) the total weight of resources below $x_{i}$. Hence individuals dislike inequity. In other words, an individual might lose well-being or utility even if he or she is at the top of the relevant income distribution. More specifically, the utility function of individual $i$ earning an amount $x_{i}$ would be:

$$
v_{i}(x)=x_{i}-\alpha_{i} \frac{1}{n-1} \sum_{j \neq i} \max \left\{x_{j}-x_{i}, 0\right\}-\beta_{i} \frac{1}{n-1} \sum_{j \neq i} \max \left\{x_{i}-x_{j}, 0\right\}
$$

The first term measures the utility gained from absolute income. The second and third terms measure the disutility that stems from upward and downward inequality ( $\alpha$ and $f$ assumed positive). Here the second term, when appropriately normalised, is closely akin to models of relative deprivation of the type used to predict mortality risk (as in Deaton, 2001) according to which relative deprivation is measured by the weight of the income distribution above a particular income (see also Kakwani, 1984; Yitzhaki, 1979).

Such an approach could be extended. In comparing one's wage $x_{i}$ with others, it seems reasonable to suppose that utility might be gained as a function of the weight of incomes below $x_{i}$, and lost as a function of the weight of incomes above $x_{i}$. Then, if 
the sign of the third term in (7) above is reversed, and $\alpha$ and $\beta$ are both positive, the Fehr-Schmidt formulation can be extended to provide a potential model of comparison-based wage utility.

This version of Fehr-Schmidt model differs from Range Frequency Theory in one important way. It assumes that higher and lower earners are weighted more heavily as their distance from $x_{i}$ increases. According to RFT, however, only the numbers of people with higher and lower incomes matter. Both models contrast with an alternative approach, developed below, in which incomes similar to $x_{i}$ carry most weight in determining the utility associated with $x_{i}$. A further difference between the Fehr-Schmidt model and RFT is that only the former can accommodate individual differences in relative concern with upward and downward comparisons. Such differences exist. For example, Stutzer (2004) found that, when income and other individual characteristics are controlled for, well-being is lower among people with higher income aspiration levels.

The principles embodied in RFT, and those incorporated in the Fehr-Schmidt model, can be seen as special cases of a more general conceptual framework. In intuitive terms, we can distinguish three different ways in which income-derived utility might be rank-dependent.

First, as in the Fehr-Schmidt model, higher and lower wages may be weighted by their difference from $x_{i}$. Such an approach receives support from the plausibility and empirical success of similar models of relative deprivation.

Second, as in RFT, the mere ordinal rank of $x_{i}$ may matter.

Third, and contrary to the Fehr-Schmidt approach, incomes relatively close to $x_{i}$ may contribute more strongly than distant incomes in determining rank-dependent utility for $x_{i}$. This idea would be consistent with the considerable weight of evidence suggesting that social comparisons occur with generally similar agents (e.g. Festinger, 1954) and that pay referents tend to be similar (e.g. Law \& Wong, 1998).

We show that these three different approaches can be captured within a single framework as follows. First, note that the rank component of RFT (equation 5) can be rewritten as:

$$
F_{i}=0.5+\frac{(i-1)-(N-i)}{2(N-1)}
$$


where $F_{i}$ is the frequency value of wage $x_{i}$ and $N$ is the number of incomes in the comparison set. Thus for a fixed comparison set, $F_{i}$ decreases linearly with the number of higher incomes $(N-i)$ and increases linearly with the number of lower incomes $(i-1)$.

A more general extension of RFT (equation 3) can now be written as follows:

$$
U_{i}(x)=w R_{i}+(1-w)\left[0.5+\frac{\alpha \sum_{j=1}^{i-1}\left(x_{i}-x_{j}\right)^{\gamma}-\beta \sum_{j=i+1}^{N}\left(x_{j}-x_{i}\right)^{\gamma}}{2\left(\alpha \sum_{j=1}^{i-1}\left(x_{i}-x_{j}\right)^{\gamma}+\beta \sum_{j=i+1}^{N}\left(x_{j}-x_{i}\right)^{\gamma}\right)}\right]
$$

where $w$ is the weighting on the range component (cf. equation 3). Note that $\alpha$ now weights downward comparisons, and $f$ weights upward comparisons.

The three models outlined earlier are special cases of equation (8), with particular values of $\gamma$ corresponding to the particular models. When $\gamma=0$, and $\alpha=\beta$, (8) reduces to Range Frequency Theory. ${ }^{\text {vi }}$ Every higher and lower income contributes equally, independently of its distance from the to-be-judged wage, in influencing the overall judgment. When $\gamma=1$, the rank-dependent component of (8) is akin to the Fehr-Schmidt model. Comparison incomes diminish utility to the extent that they are greater than $x_{i}$ and increase utility to the extent that they are less than $x_{i}$. The rangedependent component mimics the absolute component in the Fehr-Schmidt model if appropriate anchor values are assumed. When $\gamma<0$, the equation behaves as a model in which incomes close to $x_{i}$ carry greater weight. Finally, as $\gamma$ becomes $>1$, increasingly high weight is given to incomes further away from $x_{i}$.

Here we fit our generalized model to the behavior of participants in Experiment 1. In all model-fitting, we assume a constant value of $\alpha, w$, and $\gamma$ across distributions. We first fit the model to the mean data.

If $\gamma$ is set to zero, thereby mimicking RFT but with $\alpha$ and $w$ allowed to vary, an $\mathrm{R}^{2}$ value of 0.998 is obtained. In this case, the best-fitting estimates of $\alpha$ and $w$ are 1.01 and 0.36 respectively. Thus the unconstrained estimates of $\alpha$ and $f$ are close to equal as implicitly assumed by RFT. 
We next set $\gamma$ to 1 . This allows us to examine the behavior of the model derived from the Fehr-Schmidt approach. An overall $\mathrm{R}^{2}$ of 0.941 was obtained, and the best-fitting estimates of $\alpha$ and $w$ were 1.02 and 0.61 . More importantly, when as here the same parameter estimates are used for all the different distributions of hypothetical wages, the Fehr-Schmidt approach cannot accommodate the qualitative patterns in the data.

Next, we let $\gamma$ vary freely. The value of $\gamma$ was estimated at $0.0004-$ or in other words very close to the value of zero implicitly assumed by RFT. Estimates of $\alpha$ and $w$ were 1.01 and 0.36 . ${ }^{\mathrm{vi}}$

Finally, we estimated parameters for all 24 individual subjects. A median $\mathrm{R}^{2}$ of .968 was obtained, confirming that the model provided a good account of data at the level of individual subjects. Estimates of $\alpha, w$, and $\gamma$ were 1.02, 0.37, and -.004 respectively. The corresponding standard deviations were $0.12,0.16$, and 0.18 . Thus the individual-subjects analysis confirmed the key conclusions: $\alpha$ did not differ significantly from 1.0, and $\gamma$ did not differ significantly from zero.

Hence it seems that RFT, with its assumption that only the number of higher and lower earners influences utility, offers the most parsimonious account of the data. Our experimental procedure offered the potential for the data to reject RFT, as would have occurred for example if the satisfaction-wage curves had been consistently concave. Furthermore, RFT performed as well as a more general model in which the influence of contextual wages differed as a function of their difference from the target.

\section{Investigation 2: Well-being in the Workplace}

The paper's second test draws on a data set that provides both information on actual workplaces and, unusually, matched information on the characteristics of individual workers within those establishments. It uses a range of reported well-being measures, namely, a number of kinds of employee-satisfaction scores. It is known that satisfaction measures are reliable over time (see Bradburn \& Caplovitz, 1965) and correlate with measures of both mental and physical health (e.g. Palmore, 1969; Sales \& House, 1971; Wall, Clegg, \& Jackson, 1978). Furthermore, such measures are correlated with behavior (Clark, 2001; Freeman, 1978; Shields \& Ward, 2001).

Data were drawn from the United Kingdom's Workplace Employee Relations Surveys (WERS). The most recent survey was in 1997-1998 (WERS98); this was the 
first to include employee questionnaires and it is these that provide the data for the research reported here. The data set allows us to match up information on individual workers with information on the plants that employ them.

All places of employment in Britain -- including schools, shops, offices and factories -- with ten or more employees were eligible to be sampled. For this study, the usable sample is 1782 workplaces. Approximately 28,000 employees contributed completed questionnaires (a response rate of 64\%). Up to 25 employee questionnaires were distributed to randomly-selected employees within each organisation. The design of WERS98 is summarised in Cully (1998); initial findings from the study are described in Cully et al. (1998).

Employees were given self-completion questionnaires. They could return them either via the workplace or directly to the survey agency. Questions focussed on a range of issues including Employee Attitudes to Work, Payment Systems, Health \& Safety, Worker Representation, and other related areas.

The variables of particular interest to us are four measures of worker satisfaction, as listed below. Question A10 from the Survey was phrased as follows:

"How satisfied are you with the following aspects of your job?"

Four aspects were listed:

"The amount of influence you have over your job";

"The amount of pay you receive";

"The sense of achievement you get from your work", and

"The respect you get from supervisors/line managers".

A primary interest here will be on satisfaction with the amount of pay. It would not be surprising if measures such as satisfaction with influence are determined by an individual's wage rank. Because we do not have an overall job-satisfaction measure in the data set, we present satisfaction equations for all measures available.

Answers were on a five-point scale ranging from 1 (Very Satisfied) to 5 (Very Dissatisfied). A sixth "Don't Know" option was also available. For ease of interpretation, the scaling here is reversed. Thus the number 5 represents the highest level of satisfaction. The satisfaction distributions themselves have thicker tails at the upper than the lower end. For example, on satisfaction with achievement, which is representative, approximately $15 \%$ of respondents give the answer 'very satisfied', $50 \%$ say 'satisfied', $21 \%$ say 'neither satisfied nor dissatisfied', $11 \%$ say 'dissatisfied', and $4 \%$ say 'very dissatisfied'. 
The independent influences upon satisfaction include wage-related variables and background variables (which are included as controls within later regression equations). These background variables, listed in Table 2, are the age of the worker, the size of the plant, whether the worker is on a temporary contract, the educational level of the worker, gender, race, a union dummy, occupation, industry, region, hours worked by the employee, and the marital status of the employee.

It is necessary for the analysis to construct a variety of wage measures. The variables we test as determinants of well-being include:

1. $\mathrm{w}_{\mathrm{abs}}$. Weekly pay of individual $\underline{\mathrm{i}}$

2. $w_{\text {mean. }}$ Average pay in workplace $j$

3. $W_{\text {rank }}$. Rank of individual $\underline{i}$ in workplace $j$ as proportion of number of workers, where greater rank indicates the worker is, in an ordinal sense, higher up the pay scale. This rank variable is calculated as $\left(\operatorname{rank}_{\mathrm{ij}}-1\right) /($ number of observations workplace w $_{i}$ 1)

4. $\mathrm{w}_{\text {range. }}$ The distance the individual worker is up the range of $\mathrm{pay}_{\mathrm{i}}$ in workplace j. This is calculated as a proportion as: $\left(\mathrm{pay}_{\mathrm{i}}-\mathrm{pay}_{\mathrm{i}}^{\mathrm{min}}\right) /\left(\mathrm{pay}_{\mathrm{i}}{ }^{\mathrm{max}}-\mathrm{pay}_{\mathrm{i}}^{\mathrm{min}}\right)$.

For consistency with earlier literature, we work with mean wage rather than median wage. Both Rank and Range are defined so as to lie in the unit interval. Moreover, $\mathrm{w}_{\mathrm{abs}}$ and $\mathrm{w}_{\text {mean }}$ are logarithmically transformed except where otherwise stated. Finally, rank and range (and mean wage) are calculated empirically over the samples drawn from each establishment.

These different measures of pay are, of course, somewhat correlated. Nevertheless, the large number of observations makes it possible, in practice, to estimate the separate variables' effects. The paper tests whether, with other factors held constant, $\mathrm{w}_{\text {rank }}$ and $\mathrm{w}_{\text {range }}$ help to determine workers' satisfaction levels.

We generally worked with data collected from all workplaces that had at least 15 employee-pay observations. The resulting sample contained 16,266 individuals from 886 separate workplaces.

The raw correlations between the main variables are shown in Table 3. Not surprisingly, workers' reported well-being levels are in all but 3 of the 16 cases positively correlated with their (various measures of) remuneration. Four different satisfaction measures are available. These could be combined into a single average, but we decided it would be more transparent not to do so. Within Table 3, there are four wage measures. These are the log of the worker's pay, the log of mean pay in the 
plant, the worker's rank in the wage ordering, and the range of pay within the plant. Out of necessity, they are calculated within the available sample, and are thus best thought of as estimates. In other words, here the rank and range for worker i are for the sample of workers available within WERS. Compared to the true model of the whole workplace, this means that Rank and Range are measured with error, which will tend to make it harder to find statistically significant effects. The pay measures are intercorrelated, with $\mathrm{w}_{\mathrm{abs}}$ (log transformed) having a correlation greater than 0.6 with all of $\mathrm{w}_{\text {rank }}, \mathrm{w}_{\text {range, }}$ and $\mathrm{w}_{\text {mean }}(\log$ transformed). Even in the raw data depicted in Table $3, \mathrm{w}_{\mathrm{rank}}$ is more highly correlated with satisfaction than any other pay measure. For instance, in the case of a sense of achievement, the correlation coefficient is 0.086 with pay rank, compared to only 0.021 with actual pay.

Ordered probit analysis was undertaken. The background measures listed in Table 2 were always included; we do not report the coefficients for these variables, although the results are available on request. All columns in the regression tables reported below were estimated by the ordered probit technique. Standard errors are in parentheses and are robust to arbitrary heteroscedasticity and clustering bias. The Pseudo $\mathrm{R}^{2}$ values were calculated using the McKelvey-Zavoina method. Pay measures were log transformed, but the findings were checked with untransformed measures and similar results were obtained. Although, in general, ordered probit coefficients do not have the simple interpretation of OLS coefficients, we have checked that in later equations the coefficients can typically be read off in a fairly intuitive way.

After controlling for other factors, does satisfaction depend upon the level of pay? Table $4 \mathrm{a}$ shows the results for the largest possible sample. Table $4 \mathrm{~b}$ gives the results for a restricted sample that excludes small plants. There are four satisfaction equations: for Influence, Pay, Achievement and Respect. Each well-being regression equation is to be read vertically. In both the full and the restricted sample, the logarithm of absolute pay $\mathrm{w}_{\mathrm{abs}}$ has a statistically significant effect within the four satisfaction equations. The coefficients are similar in both samples. This preliminary analysis provides reassurance that the restricted sample is representative; subsequent analysis focuses on the restricted sample alone as it was deemed more reliable for analysis of $\mathrm{w}_{\text {range }}$ and $\mathrm{w}_{\text {rank }}$.

Next, we test for comparison effects. Our data are rich in that they allow us to compute the average pay within the workplace. Hence we can do a more direct test 
than Clark and Oswald (1996), who define an individual's comparison group as those workers in the data set who have similar characteristics to the individual. The result of adding $\mathrm{w}_{\text {mean }}$ into the equation is shown in Table 5. In each case, the own-wage variable, which is denoted $\operatorname{Ln}$ (pay), remains positive, and its coefficient is statistically significantly different from zero in all of the four columns. Money continues, therefore, to buy extra well-being. For Table 5's satisfaction equations for Influence, Achievement and Respect, the comparison wage $\mathrm{w}_{\text {mean }}$ enters with a negative coefficient, with a standard error generally of approximately one third of the coefficient. Interestingly, $\mathrm{w}_{\text {mean }}$ accounts for little or no significant additional variance within the $2^{\text {nd }}$ column's equation for pay satisfaction. Moreover, it has a positive sign. It is possible that this is the 'ambition' effect of Senik (2006), namely, that workers are pleased to work somewhere where their pay may rise through future promotions. But that can only be a conjecture.

To summarize, we find quite strong evidence for a relative-wage effect upon satisfaction. This is true for three of the four measures of reported well-being, and after controlling for a set of worker and workplace characteristics. Table 5 therefore adds to an accumulating econometric literature on comparison effects upon well-being.

Next, to nest Range Frequency Theory within the framework, the $\mathrm{w}_{\text {rank }}$ and $\mathrm{W}_{\text {range }}$ measures are added into each well-being equation. The results are shown in Table 6a. This is the specification for the more general model set out earlier in equation 6.

The results seem quite striking. To an economist, particularly given the likely amount of measurement error, it might be viewed as surprising that variables such as rank - where I lie in an ordinal sense in a sample of 25 workers from my establishment - partially predicts reported satisfaction with pay. Nevertheless, that is what the data seem to show.

In Table 6a, the variable measuring the individual worker's position in the pay ordering $\mathrm{w}_{\text {rank }}$ works strongly in the equations. It has an independent positive effect in a way consistent with the hypothesis of rank-dependence. This is perhaps the main finding of the paper: in both the laboratory and in real-world data there is evidence that ordinal rank matters, and indeed may matter more than the level of pay itself.

The coefficient for $\mathrm{w}_{\text {mean }}$ in the pay satisfaction equation is, rather unexpectedly, positive. ${ }^{\text {vii }}$ The coefficients on $\mathrm{w}_{\text {mean }}$ in the other three columns in Table $6 \mathrm{a}$ are not significantly different from zero at the $5 \%$ level. One possible 
(admittedly speculative) interpretation of the positive mean-wage finding is that workers view themselves as having better prospects in a highly-paid workplace. Future research will have to return to this issue.

In a search for a parsimonious specification, further analysis was carried out, in which the only pay variables were $\mathrm{w}_{\mathrm{abs}}$ with either $\mathrm{w}_{\mathrm{rank}}$ (Table $6 \mathrm{~b}$ ) or $\mathrm{w}_{\text {range }}$ (Table 6c). In these, both $\mathrm{w}_{\text {rank }}$ and $\mathrm{w}_{\text {range }}$ accounted for significant additional variance beyond that accounted for by absolute pay $\mathrm{w}_{\mathrm{abs}}$ and the background variables. It turns out that the Rank variable somewhat outperforms the Range variable.

How broad is the comparison sample that provides the context? Do workers ever really compare themselves with a person like Bill Gates? A further analysis aimed to accommodate the idea that comparison for an individual might take place within the same occupational category.

One might hypothesize that two processes are involved in the determination of satisfaction. The first requires that a comparison or contextual set is chosen, while the second process involves the decision about an overt satisfaction rating. Our paper is concerned primarily with the second process, but it is likely that the first process involves some kind of 'similarity-based' sampling. For example, one might include in one's comparison set those people of similar age and wage to oneself, those people in similar occupations, and those who are geographically close (Bygren, 2004; Festinger, 1954; Law \& Wong, 1998). According to Kahneman and Miller's (1986) Norm Theory, a stimulus or event is judged and interpreted in the context of an evoked set of relevant stimuli or events that are retrieved (often due to their similarity) by the event to be judged. There is evidence that human memory works in a way that would lead to formation of such a comparison set (e.g. Brown, Neath, \& Chater, 2007; Hintzman, 1986; Nosofsky, 1986).

The analysis attempted to address this issue. This was done by examining a subset of the WERS98 data that could take into account people's type of work (using Occupational Group codes). We confined analysis to the largest occupational group within an organisation, and used only cases where there were at least 10 employee observations in that largest occupation. This reduced the sample size to 4744 individuals from 373 separate workplaces. The results were essentially identical to those obtained in the larger analyses on groups not differentiated by occupation, although the effect of $w_{\text {range }}$ was weaker. Here we report only the final analyses those that examine, separately, the effects of $\mathrm{w}_{\text {rank }}$ and of $\mathrm{w}_{\text {range }}$ when the effects of 
$\mathrm{w}_{\mathrm{abs}}$, are partialled out. The results are in Tables $7 \mathrm{a}$ and $7 \mathrm{~b}$. It is evident that wage satisfaction, as well as most other satisfaction measures, is independently predicted by $\mathrm{w}_{\text {rank }}$. As before, the Rank effect is positive and seems highly robust. Because of the size of the sample, it was not possible to estimate simultaneously the effects of range and rank in workplaces and occupations.

Although the emphasis here has been on whether rank and range have statistically significant effects, their size is also of interest. As one fairly representative example, consider the variable 'satisfaction with achievement'. In this case, a movement in Rank from zero to unity raises quite noticeably the likelihood of being satisfied. The probability of giving either the top or second-top satisfaction answer here increases, holding the other independent variables constant, from approximately $61 \%$ to $70 \%$. To put this in perspective, in most specifications the level of absolute pay would have to more than triple to get the same effect.

Some potential criticisms and counter-arguments should be mentioned.

- First, there is no guarantee in these workplaces that workers actually know other people's wage rates. All we can say is that people act as though they are able to form a reasonable estimate of where, as individuals, they lie in the pay ordering and the range. It would be interesting to examine plants and offices with confidential pay scales, and to ascertain whether people want others to be able to see that they are high in income-rank.

- Second, it seems important to understand exactly how a person chooses a reference group. Our paper has little to contribute to this issue. We are forced in our econometric specification simply to assume that the workplace is the comparison set.

- Third, given the sometimes positive nature of comparisons in the pay satisfaction equations, it would be interesting to be able to say more about the lifetime dynamics of pay. Low wages today may be compensated by high wages after promotion tomorrow. More research here will be needed.

- Fourth, we are unable to control directly for job titles, and this kind of 'rank' is likely also to play a role in well-being, even though it is unobservable in our data set. 
- Fifth, without enormous samples, measurement error is inevitably a problem in the construction of our Rank and Range variables. In this study, probably the best that can be done is to check, as we have done, that the findings go through for sub-samples of small as well as large workplaces.

- Sixth, in principle, it might be that wage variables such as Rank are merely proxying for an omitted non-linearity in the form that absolute pay takes in the well-being equations. Our checks with higher-order pay polynomials, however, suggest that this is not the explanation.

- Seventh, it might perhaps be argued that an allowance for additional 'moments' of the pay distribution is bound to improve upon simpler specifications, so that, by Occam's razor, standard models should be preferred. Yet that objection seems to miss the key point. Our data suggest that, when a direct comparison is done, a rank variable strongly outperforms a simple relative-wage variable.

- Eighth, could it be that Rank is merely a proxy for omitted variables like job autonomy, and it is those omitted factors that raise well-being? It is never feasible in empirical research to dispose entirely of this kind of possibility. Nevertheless, the first section of the paper shows that RFT fits the data in an experimental setting where there is no influence from job characteristics like autonomy.

\section{Investigation 3: Quits in Workplace Data}

Up to this point, the paper has concentrated on reported levels of well-being, and has viewed those numbers as providing proxy utility data. Such an approach seems to be of some worth in its own right. It also fits with much recent literature, such as Luttmer (2005). However, to show that RFT also has implications for observable actions, we now estimate labor-turnover equations.

Information on the individual workers who choose to leave is not available within our data set. Hence it is not possible to do a micro-data test on people's labor turnover decisions.

Nevertheless, workplaces do provide data on the total number of quits in the previous year. This makes it possible, by using information on workplace size, to 
calculate the quit rate per plant. Range Frequency Theory has the implication that workers will tend to quit more when -- following a version of equation 6 -- the distribution of wages at the plant produces a low level of utility from the job.

A key prediction of RFT is that negative skewness of a pay distribution leads to workers who are more content. This prediction arises because the mean level of happiness is greater if the majority of workers are near the top of the salary range paid by the employer. Will a measure of the skewness of wages independently predict the level of quits in a regression equation? We construct a test of this sort.

After discarding the plants where fewer than 15 workers provided details to the survey, we are left with a usable sample of approximately 900 workplaces. Table 8 describes the raw data. The quit rate in the sample is approximately $14 \%$ of employees per annum. Mean pay in the sample is approximately 258 pounds per week. It is also useful to have a measure of dispersion. Within plants, the standard deviation of pay is 147 pounds per week. Skewness of pay is here defined as:

$$
\frac{\sum_{i=1}^{N}\left(Y_{i}-\bar{Y}\right)^{3}}{(N-1) s^{3}}
$$

where $\mathrm{Y}_{i}$ is the $i$ th wage and $s$ is the standard deviation. Its mean value is approximately unity.

Public and private sectors may have rather different kinds of labor turnover processes. There is close to de facto 'tenure' in the British public sector. In Table 9, the two samples are simply combined, with an intercept-shift dummy for the public sector. The dependent variable is given by answers to the following question: "During the last twelve months how many permanent employees (full and part time) stopped working here, because they ... left or resigned voluntarily?".

Column 1 of Table 9 is a parsimonious ordinary-least-squares quits equation in which pay, the standard deviation of pay, and skewness of pay are included as the only independent variables (a more formal logit equation gave the same results). This is not to be thought of as a general model, but it can be seen in column 1 of Table 9 that quits are lower in high-paying plants. They are also higher where pay is more positively skewed (see coefficient 0.018 with a standard error of 0.006). This is consistent with Range Frequency Theory. 
Column 2 of Table 9 adds in region dummies, industry dummies (to try to account for, among other things, 'sunset technologies' where there is high level of quits), a public-sector dummy, and measure of workplace size. The coefficient on Skewness falls somewhat, from 0.18 to 0.10 , and marginally loses significance at the 5\% level. However, a fuller, and arguably the most natural, specification is set out in the third and final column of Table 9. Here the quits equation allows also for a number of controls of the sort suggested by labor economics -- including the proportion of people with occupational pensions, whether the workplace is formally unionized, the proportion of female workers, and two variables that capture the age composition of the workplace. Now the coefficient on the skewness variable is estimated at 0.12 . This coefficient is significantly different from zero at the $5 \%$ level. Moreover, on these estimates, the effect that the shape of the pay distribution has upon quits is not trivially small. A one-standard-deviation increase in Skewness here raises the quit rate by a little more than one percentage point per annum. This is close in size to, for example, the effect of a one-standard-deviation drop in the proportion of workers over 50 years of age.

Standard deviation of pay does not enter statistically significantly in the equations, but is retained as a control to ensure that skewness is not standing in for some simpler measure of the second moment of a distribution. Nothing of substance alters by removing the standard-deviation variable from the regressors. We also checked whether various controls for workers' education levels entered the quits equation, but their coefficients were never statistically significantly different from zero.

Table 10 gives the equivalent quits equation for private-sector workers alone. Our sample size is now slightly less than 600 workplaces, and the coefficients are not always precisely estimated. But the broad pattern is the same. Skewness enters in a statistically significant way in columns 2 and 3 of Table 10 . Here the coefficient is approximately 0.02 , and again the standard deviation of skewness is approximately unity, so the size of this effect is actually a little larger than in the public-plus-privatesector full sample. Once again, the findings are consistent with a Parducci-style model.

Finally, we experimented with another variable -- one for the average value of 'range' within each establishment. This mean range variable worked with the correct sign but its t-statistic was not reliably larger than 2 . Our instinct is that skewness here is a better measure theoretically, because it goes some way to capture the fact that it is 
disproportionately the workers low down a pay distribution who are likely to quit. As explained earlier, skewness is also directly emphasised by Parducci.

\section{Conclusion}

This paper is an attempt to understand wage comparisons and the determinants of well-being in the workplace. By combining laboratory and econometric evidence, the paper draws three conclusions.

First, human beings do not care solely about their absolute level of pay. Workers are concerned, the paper shows, with their income relative to the remuneration levels around them in their workplace. In this sense, the work is in the spirit of a tradition that includes in the modern era Frank (1985), Clark and Oswald (1996) and Luttmer (2005), and before them Duesenberry (1949). Comparisons matter.

Second, although we uncover some econometric evidence for a simple relative-income formulation in which utility is given by a function $u=u$ (pay, relative pay), the main contribution of the paper is an attempt to go beyond this. Using a sample of 16,000 workers from 900 workplaces, the paper argues that ordinal rank has a statistically significant effect upon well-being, and that to understand what makes human beings content it is therefore necessary to look at the whole distribution of incomes. The paper appears to be one of the first in the industrial relations and economics literatures to provide workplace evidence for the importance of income rank.

Third, using data on quits, the paper finds evidence that greater positiveskewness in the pay distribution is, as Allen Parducci's work predicts, associated with higher labor turnover.

It is natural to think of possible evolutionary motives behind a concern for ordinal position among human beings, but it is currently not possible to say exactly why rank, range and skewness have the effects we observe in workplace data. Nevertheless, the results in this paper suggest that Range Frequency Theory -- a conceptual account still unknown to most economists and industrial relations researchers -- may be valuable to the disciplines of labor economics and industrial relations. 


\section{References}

Akerlof, George A., and Janet L. Yellen. 1990. "The Fair Wage-effort Hypothesis and Unemployment.” Quarterly Journal of Economics 105 (May):255-283.

Birnbaum, Michael H. 1992. "Violations of Monotonicity and Contextual Effects in Choice-Based Certainty Equivalents.” Psychological Science 3 (September):310-314.

Blanchflower, David, and Andrew J. Oswald. 2004. "Well-being over Time in Britain and the USA." Journal of Public Economics 88 (July):1359-1386.

Bolton, Gary E. 1991. "A Comparative Model of Bargaining: Theory and Evidence." American Economic Review 81 (December):1096-1136.

Borowiak, Dale S. 1989. Model Discrimination for Nonlinear Regression Models. New York: Marcel Dekker.

Boskin, Michael, and Eytan Sheshinski. 1978. "Optimal Redistributive Taxation when Individual Welfare Depends upon Relative Income.” Quarterly Journal of Economics 92 (November):589-601.

Bradburn, Norman, and David Caplovitz. 1965. Reports on Happiness. Chicago, IL: Aldine.

Brown, Gordon D.A., Neath, Ian., and Nick Chater. 2007. "A Temporal Ratio Model of Memory.” Psychological Review 114 (July):539-576.

Brown, Gordon D.A., and Jing Qian. 2004. "The Origin of Probability Weighting: A Psychophysical Approach.” Manuscript Submitted for Publication.

Bygren, Magnus. 2004. "Pay Reference Standards and Pay Satisfaction: What Do Workers Evaluate Their Pay Against?' Social Science Research 33 (June):206224.

Cappelli, Peter, and Peter D. Sherer. 1988. "Satisfaction, Market Wages, and Labor Relations: An Airline Study.” Industrial Relations 27 (January):56-73.

Clark, Andrew E. 2000. "Is Utility Absolute or Relative? Some Recent Findings." Revue Economique 51 (May):459-471.

Clark, Andrew E. 2001. "What Really Matters In A Job? Hedonic Measurement Using Quit Data.” Labour Economics 8 (May): 223-242.

Clark, Andrew E. 2003. "Unemployment as a Social Norm: Psychological Evidence from Panel Data.” Journal of Labor Economics 21 (April):323-351.

Clark, Andrew E., and Andrew J. Oswald. 1996. "Satisfaction and Comparison Income." Journal of Public Economics 61 (September):359-381. 
Cox, James, and Ronald Oaxaca. 1989. "Laboratory Experiments With a Finite Horizon Job Search Model." Journal of Risk and Uncertainty 2 (September):301-329.

Cully, Mark. 1998. A Survey in Transition: The Design of the 1998 Workplace Employee Relations Survey. London: Department of Trade and Industry.

Cully, Mark, Woodland, Stephen, O’Reilly, Andrew, Dix, Gill, Millward, Neil, Bryson, Alex, and John Forth. 1998. The 1998 workplace employee relations survey: First findings. London: Department of Trade and Industry.

Deaton, Angus. 2001. "Relative Deprivation, Inequality, and Mortality”. Unpublished manuscript.

Di Tella, Rafael., and Robert MacCulloch. 2005. "Social Partisan Happiness." Review of Economic Studies 72 (April):367-393.

Easterlin, Richard A. 1974. "Does Economic Growth Improve the Human Lot? Some Empirical Evidence.” In Nations and Households in Economic Growth: Essays in Honor of Moses Abramowitz, edited by Paul A. David and Melvin W. Reder. New York: Academic Press.

Easterlin, Richard A. 1995. "Will Raising the Incomes of All Increase the Happiness of All?’ Journal of Economic Behavior and Organization 27 (June):35-48.

Fehr, Ernst, and Klaus M. Schmidt. 1999. "A Theory of Fairness, Competition, and Cooperation.” Quarterly Journal of Economics 114 (August):817-868.

Fehr, Ernst, and Klaus M. Schmidt. 2001. "Theories of Fairness and ReciprocityEvidence And Economic Applications.” CEPR Discussion Paper Series, February.

Festinger, Leon. 1954. "A Theory of Social Comparison Processes." Human Relations 7 (May):117-140.

Frank, Robert H. 1985. Choosing the Right Pond: Human Behaviour and the Quest for Status. London: Oxford University Press.

Freeman, Richard B. 1978. "Job Satisfaction as an Economic Variable." American Economic Review 68 (May):135-141.

Frey, Bruno S., and Alois Stutzer. 2002. Happiness and Economics. Princeton and Oxford: Princeton University Press.

Gilboa, Itzhak., and David Schmeidler. 2001. “A Cognitive Model of Individual Well-Being." Social Choice Welfare 18 (2):269-288 
Goodman, Paul S. 1974. "An Examination of Referents Used in the Evaluation of Pay." Organizational Behavior and Human Performance 12 (October):170-195. Groot, Wim, and Henriette M. Van Den Brink. 1999. “Overpayment and Earnings Satisfaction: An Application of an Ordered Response Tobit Model." Applied Economics Letters 6 (April):235-238.

Hagerty, Michael R. 2000. "Social Comparisons of Income in One's Community: Evidence from National Surveys of Income and Happiness." Journal of Personality and Social Psychology 78 (April):764-771.

Helson, Harry. 1964. Adaptation-Level Theory. Oxford, England: Harper and Row.

Hamermesh, Daniel S. 1975. Interdependence in the labor market. Economica 42 (November):420-429.

Highhouse, Scoot, Brooks-Laber, Margaret E., Lin, Lilly, and Christiane Spitzmueller. 2003. "What Makes a Salary Seem Reasonable? Frequency Context Effects on Starting-Salary Expectations." Journal of Occupational and Organizational Psychology 76 (March):69-81.

Hills, Frederick S. 1980. "The Relevant Other In Pay Comparisons." Industrial Relations 19 (Fall):345-350.

Hintzman, Douglas L. 1986. "Schema Abstraction in a Multiple-Trace Memory Model.” Psychological Review 93 (October):411-428.

Hopkins, Ed, and Tatiana Kornienko. 2004. "Running to Keep in the Same Place: Consumer Choice as a Game of Status." American Economic Review 94 (September):1085-1107.

Janiszewski, Chris and Donald R. Lichtenstein. 1999. "A Range Theory Account of Price Perception.” Journal of Consumer Research 25 (March):353-368.

Kahneman, Daniel. 1992. "Reference Points, Anchors, Norms, and Mixed Feelings." Organizational Behavior and Human Decision Processes 51 (March):296-312.

Kahneman, Daniel, and Dale T. Miller. 1986. "Norm Theory: Comparing Reality to its Alternatives." Psychological Review 93 (April):136-153.

Kahneman, Daniel, and Amos Tversky. 1979. "Prospect Theory: An Analysis of Decision under Risk." Econometrica 47 (March):263-291.

Kakwani, Nanak. 1984. "The Relative Deprivation Curve and its Applications." Journal of Business \& Economic Statistics 2 (October):384-394.

Kapteyn, Arie., and Tom Wansbeek. 1985. "The Individual Welfare Function: A Review." Journal of Economic Psychology 6 (December):333-363. 
Kornienko, Tatiana. 2004. "A Cognitive Basis for Cardinal Utility." Unpublished manuscript.

Kosicki, George. 1987. "A Test of the Relative Income hypothesis." Southern Economic Journal 54 (October):422-434.

Law, Kenneth S., and Chi-Sum Wong. 1998. "Relative Importance of Referents on Pay Satisfaction: A Review and Test of a New Policy-capturing Approach." Journal of Occupational and Organizational Psychology 71 (March):47-60.

Layard, Richard. 1980. "Human Satisfactions and Public Policy." Economic Journal 90 (December):737-750.

Layard, Richard. 2005. Happiness: Lessons from a New Science. London: Allen-Lane. Levine, David I. 1993. "Fairness, Markets, and Ability to Pay: Evidence from Compensation Executives." American Economic Review 83 (December):12411259.

Lommerud, Kjell E. 1989. "Educational Subsidies when Relative Income Matters." Oxford Economic Papers 41 (July):640-652.

Lopes, Lola L. 1987. "Between Hope and Fear: The Psychology of Risk." In Advances in Experimental Social Psychology (Vol. 20), edited by Leonard Berkowitz, pp.255-295. San Diego, CA: Academic Press.

Luttmer, Erzo. 2005. "Neighbors as Negatives: Relative Earnings and Well-being." Quarterly Journal of Economics 120 (August):963-1002.

Marmot, Michael G. 1994. "Social Differences in Health within and between Populations." Daedalus 123 (Fall):197-216.

Marmot, Michael G., \& Bobak, Martin. 2000. "International Comparators and Poverty and Health in Europe." British Medical Journal 321 (November):1124-1128.

McBride, Michael. 2001. "Relative-income Effects on Subjective Well-being in the Cross-section." Journal of Economic Behavior and Organization 45 (July):251278.

Mellers, Barbara A. 1982. "Equity Judgment: A Revision of Aristotelian Views." Journal of Experimental Psychology: General 111 (June):242-270.

Mellers, Barbara A. 1986. "“Fair" allocations of salaries and taxes." Journal of Experimental Psychology: Human Perception and Performance 12 (1):80-91.

Mellers, Barbara A., Ordoñez, Lisa D., and Michael H.Birnbaum. 1992. "A Changeof-process Theory for Contextual Effects and Preference Reversals in Risky 
Decision Making." Organizational Behavior and Human Decision Processes 52 (August):331-369.

Munro, Alistair, and Robert Sugden. 2003. "On the Theory of Reference-dependent Preferences." Journal of Economic Behavior and Organization 50 (April):407428.

Niedrich, Ronald W., Sharma, Subhash, and Douglas H. Wedell. 2001. "Reference Price and Price Perceptions: A Comparison of Alternative Models." Journal of Consumer Research 28 (December):339-354.

Nosofsky, Robert M. 1986. "Attention, Similarity and the Identificationcategorization Relationship." Journal of Experimental Psychology: General 115 (March):39-57.

Ok, Efe A., and Levent Koçkesen. 2000. "Negatively Interdependent Preferences." Social Choice and Welfare, 17 (May):533-558.

Ordoñez, Lisa.D., Connolly, Terry, and Richard Coughlan. 2000. "Multiple Reference Points in Satisfaction and Fairness Assessment." Journal of Behavioral Decision Making 13 (July):329-344.

Oswald, Andrew J. 1983. "Altruism, Jealousy and the Theory of Optimal Non-linear Taxation." Journal of Public Economics 20 (February):77-88.

Oswald, Andrew J. 1997. "Happiness and Economic Performance." Economic Journal 107 (November):1815-1831.

Oswald, Andrew J. and Nattavudh Powdthavee. 2007. "Obesity, Unhappiness and the Challenge of Affluence: Theory and Evidence." Economic Journal, forthcoming.

Palmore, Erdman. 1969. "Predicting Longevity: A Follow-up Controlling for Age." Gerontologist 9 (4):247-250.

Parducci, Allen. 1965. "Category Judgment: A Range-frequency Theory." Psychological Review 72 (November):407-418.

Parducci, Allen. 1995. Happiness, Pleasure, and Judgment: The Contextual Theory and its Applications. Mahwah, NJ: Erlbaum.

Patchen, Martin. 1961. The Choice of Wage Comparisons. Englewood Cliffs, NJ: Prentice-Hall.

Rabin, Matthew. 1993. "Incorporating Fairness into Game Theory and Economics." American Economic Review 83 (December):1281-1302.

Rees, Albert. 1993. "The Role of Fairness in Wage Determination." Journal of Labor Economics 11 (January):243-252. 
Runciman, W. Garry. 1966. Relative Deprivation and Social Justice. London: RKP. Sales, Stephen. M., and James House. 1971. "Job Dissatisfaction as a Possible Risk Factor in Coronary Heart Disease." Journal of Chronic Diseases 23 (May):861873.

Samuelson, Larry. 2004. "Information-based Relative Consumption Effects." Econometrica 72 (January):93-118.

Schmeidler, David. 1989. "Subjective Probability and Expected Utility without Additivity." Econometrica 57 (May):571-587.

Seidl, Christian, Traub, Stefan, and Andrea Morone. 2003. "Relative Deprivation, Personal Income Satisfaction, and Average Well-being under Different Income Distributions." Unpublished manuscript. Christian-Albrechts-University of Kiel. Senik, Claudia. 2006. "Ambition and Jealousy: Income Interactions in the "Old" Europe versus the "New" Europe and the United States." IZA Discussion Papers 2083, Institute for the Study of Labor (IZA).

Shields, Michael, and Melanie Ward. 2001. "Improving Nurse Retention in the National Health Service in England: The Impact of Job Satisfaction on Intentions to Quit." Journal of Health Economics 20 (September):677-701.

Smith, Richard H., Diener, Ed., and Douglas H. Wedell. 1989. "Interpersonal and Social Comparison Determinants of Happiness: A Range-frequency Analysis." Journal of Personality and Social Psychology 56 (March):317-325.

Stewart, Neil., Chater, Nick., and Gordon D.A. Brown. 2006. "Decision by Sampling." Cognitive Psychology 53 (August):1-26.

Stutzer, Alois. 2004. "The Role of Income Aspirations in Individual Happiness." Journal of Economic Behavior \& Organization 54 (May):89-109.

Van Praag, Bernard M.S. 1968. Individual Welfare Functions and Consumer Behavior: A Theory of Rational Irrationality. North-Holland, Amsterdam.

Van Praag, Bernard M.S. 1971. "The Welfare Function of Income in Belgium: An empirical investigation." European Economic Review 2 (Spring):337-369.

Volkmann, John. 1951. "Scales of Judgment and Their Implications for Social Psychology." In Social Psychology at the Crossroads: The University of Oklahoma Lectures in Social Psychology, edited by John H. Rohrer and Muzafer Sherif, pp. 273-294. New York: Harper and Row. 
Wall, Toby D., Clegg, Chris W., and Paul R. Jackson. 1978. "An Evaluation of the Job Characteristics Model." Journal of Occupational Psychology 51 (June):183196.

Yitzhaki, Shlomo. 1979. "Relative Deprivation and the Gini Coefficient." Quarterly Journal of Economics 93 (May):321-324.

Zizzo, Daniel J. 2002. "Between Utility and Cognition: The Neurobiology of Relative Position." Journal of Economic Behavior \& Organization 48 (May):71-91. 
Footnotes

${ }^{\text {i }}$ E.g. Bolton, 1991; Capelli \& Sherer, 1988; Goodman, 1974; Hills, 1980; Law \& Wong, 1998; McBride, 2001; Patchen, 1961.

${ }^{\text {ii }}$ For example, in Blanchflower \& Oswald, 2004; Bolton, 1991; Clark, 2000; Easterlin, 1995; Frey \& Stutzer, 2002; Ok \& Kockesen, 2000; for earlier research see e.g. Boskin \& Sheshinski, 1978; Frank, 1985; Kosicki, 1987; Layard, 1980; Lommerud, 1989; Oswald, 1983, 1997.

iii See Easterlin, 1974; Frank, 1985; Hopkins \& Kornienko, 2004; Kapteyn \& Wansbeek, 1985; Kornienko, 2004; Van Praag, 1968, 1971.

${ }^{\text {iv }}$ E.g. Birnbaum, 1992; Brown \& Qian, 2004; Hagerty, 2000; Mellers, Ordonez, \& Birnbaum, 1992; Niedrich, Sharma, \& Wedell, 2001; Smith et al., 1989; Stewart, Chater, \& Brown, 2006.

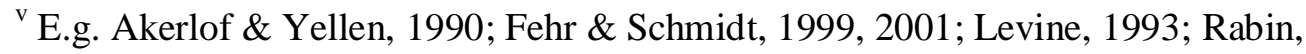
1993.

${ }^{\mathrm{vi}}$ This is most transparent when $\alpha=\beta=1$. As estimation of both $\alpha$ and $\beta$ is redundant (equation 8 ) we set $f$ to 1.0 and estimate only $\alpha$.

${ }^{\text {vii }}$ We also examined the behavior of a model in which the distances between wages prior to transformation by $\gamma$ were assumed to be given by their ratio rather than by the absolute difference between them. Such a model fits the data equally well. Here, however, we maintain a focus on absolute differences to preserve comparability with the Fehr-Schmidt approach.

viii This effect was smaller in the analysis in which pay values were not logarithmically transformed. 
Table 1

The Hypothetical Annual Wages Used in Six Pay Distributions in Investigation 1

\begin{tabular}{cccccccccccc}
\hline Pos Skew & 17.2 & 17.6 & 18.1 & 18.7 & 19.5 & 20.3 & 21.4 & 22.7 & 24.3 & 26.1 & 28.4 \\
Neg Skew & 17.2 & 19.5 & 21.3 & 22.9 & 24.2 & 25.3 & 26.1 & 26.9 & 27.5 & 28.0 & 28.4 \\
Unimodal & 17.2 & 20.0 & 21.5 & 22.2 & 22.6 & 22.8 & 23.0 & 23.4 & 24.1 & 25.6 & 28.4 \\
Bimodal & 17.2 & 17.4 & 17.8 & 18.5 & 20.0 & 22.8 & 25.6 & 27.1 & 27.8 & 28.2 & 28.4 \\
Low Range & 14.3 & 17.1 & 18.6 & 20.0 & 21.4 & 22.8 & 25.9 & 26.8 & 27.5 & 28.0 & 28.4 \\
High Range & 17.2 & 17.6 & 18.1 & 18.8 & 19.7 & 22.8 & 24.2 & 25.6 & 27.1 & 28.5 & 31.3 \\
\hline
\end{tabular}

Note: 17.2 means a value of $£ 17,200$ pounds sterling 
Table 2

\section{Control Variables Used in all Regressions in Investigation 2}

\begin{tabular}{l}
\hline Measure \\
\hline Age (of the worker) \\
Employer size \\
Whether a temporary job \\
Education \\
Gender \\
Race \\
Union recognition at the workplace \\
Occupation (SOC Code at the one-digit level) \\
Industry (SIC code at the two-digit level) \\
Region \\
Hours worked \\
Marital status
\end{tabular}

Definitions Marriage is "living with spouse or partner". Race is "white or non-white". Region is the standard statistical regions of the United Kingdom. Education is the "highest educational qualification you hold" in six bands from None to Postgraduate Degree. 
Table 3

Correlation Matrix

Total sample: 14703 observations

\begin{tabular}{|c|c|c|c|c|c|c|c|c|}
\hline & $\begin{array}{l}\text { Satisfaction } \\
\text { with } \\
\text { Influence } \\
\end{array}$ & $\begin{array}{l}\text { Satisfaction } \\
\text { with Pay }\end{array}$ & $\begin{array}{c}\text { Satisfaction } \\
\text { with } \\
\text { Achievement }\end{array}$ & $\begin{array}{l}\text { Satisfaction } \\
\text { with } \\
\text { Respect } \\
\end{array}$ & Ln(pay) & $\begin{array}{l}\text { Ln(mean } \\
\text { pay) }\end{array}$ & Rank & Range \\
\hline $\begin{array}{l}\text { Satisfaction } \\
\text { with } \\
\text { Influence }\end{array}$ & 1.000 & & & & & & & \\
\hline $\begin{array}{c}\text { Satisfaction } \\
\text { with Pay }\end{array}$ & 0.339 & 1.000 & & & & & & \\
\hline $\begin{array}{l}\text { Satisfaction } \\
\text { with }\end{array}$ & 0.523 & 0.312 & 1.000 & & & & & \\
\hline $\begin{array}{c}\text { Achievement } \\
\text { Satisfaction } \\
\text { with Respect }\end{array}$ & 0.523 & 0.348 & 0.499 & 1.000 & & & & \\
\hline Ln(pay) & 0.041 & 0.083 & 0.021 & -0.021 & 1.000 & & & \\
\hline $\begin{array}{l}\operatorname{Ln}(\text { mean } \\
\text { pay) }\end{array}$ & 0.005 & 0.062 & -0.021 & -0.030 & 0.680 & 1.000 & & \\
\hline Rank & 0.095 & 0.119 & 0.086 & 0.046 & 0.643 & 0.042 & 1.000 & \\
\hline Range & 0.072 & 0.116 & 0.072 & 0.024 & 0.673 & 0.134 & 0.801 & 1.000 \\
\hline
\end{tabular}

- 'Rank' is the ordinal position of the worker's wage in the hierarchy of wage levels being paid in the workplace.

- 'Range' is the worker's distance along the interval of wages being paid in the workplace.

- Both rank and range are normalized to lie in an interval between zero and one.

\section{Summary statistics}

The means (and standard deviations in parentheses) of the variables in the data set are as follows: satisfaction with influence 3.53 (s.d. 0.95); satisfaction with pay 2.90 (1.10); satisfaction with achievement 3.60 (1.00); satisfaction with respect 3.47 (1.11); pay 302.76 (222.53); log of pay 5.43 (0.82); mean pay 300.66 (142.35); log of mean pay $5.58(0.52)$; rank $0.41(0.31)$; range $0.37(0.31)$. $\operatorname{Ln}$ (mean pay) stands for the log of mean pay, and not the mean of log pay. 
Table 4a

Well-being Regression Equations with Absolute Pay as an Independent Variable (Standard errors are in parentheses)

\begin{tabular}{l|rrrr}
\hline & $\begin{array}{l}\text { Satisfaction } \\
\text { with } \\
\text { Influence }\end{array}$ & $\begin{array}{c}\text { Satisfaction } \\
\text { with Pay }\end{array}$ & $\begin{array}{c}\text { Satisfaction } \\
\text { with } \\
\text { Achievement }\end{array}$ & $\begin{array}{r}\text { Satisfaction } \\
\text { with Respect }\end{array}$ \\
\hline Ln(pay) & 0.128 & 0.556 & 0.119 & 0.057 \\
& $(0.021)$ & $(0.026)$ & $(0.021)$ & $(0.022)$ \\
\#Observations & & & & \\
Workplaces & 1744 & 1744 & 1744 & 1744 \\
Individuals & 21862 & 21862 & 21862 & 21862 \\
Log-L & -28167.4 & -30237.5 & -28294.2 & -30508.6 \\
Pseudo R & 0.065 & 0.116 & 0.086 & 0.063 \\
\hline
\end{tabular}

Each column is a separate kind of satisfaction equation. $\operatorname{Ln}$ (pay) is the log of weekly pay. The other controls in the regression equations are as listed in Table 2.

Table 4b

\begin{tabular}{l|rrrr}
\hline & $\begin{array}{c}\text { Satisfaction } \\
\text { with Influence }\end{array}$ & $\begin{array}{c}\text { Satisfaction } \\
\text { with Pay }\end{array}$ & $\begin{array}{c}\text { Satisfaction } \\
\text { with } \\
\text { Achievement }\end{array}$ & $\begin{array}{l}\text { Satisfaction } \\
\text { with Respect }\end{array}$ \\
\hline Ln(pay) & 0.144 & 0.577 & 0.127 & 0.084 \\
& $(0.026)$ & $(0.034)$ & $(0.026)$ & $(0.028)$ \\
\#Observations & & & & \\
Workplaces & 897 & 897 & 897 & 897 \\
Individuals & 14703 & 14703 & 14703 & 14703 \\
Log-L & -18830.8 & -20229.4 & -18943.2 & -20351.7 \\
Pseudo R & 0.070 & 0.127 & 0.090 & 0.064 \\
\hline
\end{tabular}

This table uses only those workplaces in the data set where responses are available from at least 15 workers. 
Table 5

Well-being Regression Equations with Pay and Mean Pay in the Workplace as Independent Variables

(Standard errors are in parentheses)

\begin{tabular}{l|rrrr}
\hline & $\begin{array}{l}\text { Satisfaction } \\
\text { with } \\
\text { Influence }\end{array}$ & $\begin{array}{c}\text { Satisfaction } \\
\text { with Pay }\end{array}$ & $\begin{array}{c}\text { Satisfaction } \\
\text { with } \\
\text { Achievement }\end{array}$ & $\begin{array}{c}\text { Satisfaction with } \\
\text { Respect }\end{array}$ \\
\hline Ln(pay) & 0.171 & 0.554 & 0.159 & 0.115 \\
Ln(mean pay) & $(0.026)$ & $(0.033)$ & $(0.027)$ & $(0.029)$ \\
& -0.092 & 0.077 & -0.108 & -0.105 \\
\#Observations & $(0.035)$ & $(0.041)$ & $(0.034)$ & $(0.038)$ \\
Workplaces & & & & \\
Individuals & & & & 897 \\
Log-L & 14703 & 14703 & 14703 & 14703 \\
Pseudo R ${ }^{2}$ & -18826.2 & -20226.1 & -18936.9 & -20345.7 \\
\hline
\end{tabular}

$\mathrm{Ln}$ (mean pay) is the log of mean weekly pay in the workplace.

The other controls in the regression equations are as listed in Table 2. 


\section{Table 6a}

Well-being Regression Equations with Pay, Mean Pay, Rank and Range as Independent Variables

(Standard errors are in parentheses)

\begin{tabular}{|c|c|c|c|c|}
\hline & $\begin{array}{l}\text { Satisfaction } \\
\text { with } \\
\text { Influence }\end{array}$ & $\begin{array}{l}\text { Satisfaction } \\
\text { with Pay }\end{array}$ & $\begin{array}{c}\text { Satisfaction } \\
\text { with } \\
\text { Achievement }\end{array}$ & $\begin{array}{l}\text { Satisfaction } \\
\text { with Respect }\end{array}$ \\
\hline \multirow[t]{2}{*}{ Ln(pay) } & -0.013 & 0.297 & 0.047 & 0.010 \\
\hline & $(0.040)$ & (0.048) & $(0.040)$ & $(0.042)$ \\
\hline \multirow[t]{2}{*}{ Ln(mean pay) } & 0.086 & 0.319 & -0.000 & 0.000 \\
\hline & $(0.046)$ & (0.059) & $(0.046)$ & $(0.050)$ \\
\hline \multirow[t]{2}{*}{ Rank } & 0.359 & 0.356 & 0.215 & 0.256 \\
\hline & $(0.062)$ & $(0.071)$ & $(0.066)$ & $(0.066)$ \\
\hline \multirow[t]{2}{*}{ Range } & 0.065 & 0.244 & 0.041 & -0.015 \\
\hline & $(0.063)$ & $(0.069)$ & $(0.064)$ & $(0.064)$ \\
\hline \multicolumn{5}{|l|}{ \#Observations } \\
\hline Workplaces & 897 & 897 & 897 & 897 \\
\hline Individuals & 14703 & 14703 & 14703 & 14703 \\
\hline Log-L & -18803.1 & -20185.7 & -18928.6 & -20335.9 \\
\hline Pseudo $\mathrm{R}^{2}$ & 0.074 & 0.133 & 0.093 & 0.067 \\
\hline
\end{tabular}

The other controls in the regression equations are as listed in Table 2.

Table 6b

Well-being Regression Equations with Pay and Rank as Independent Variables

\begin{tabular}{l|rrrr}
\hline & $\begin{array}{l}\text { Satisfaction } \\
\text { with } \\
\text { Influence }\end{array}$ & $\begin{array}{c}\text { Satisfaction } \\
\text { with Pay }\end{array}$ & $\begin{array}{c}\text { Satisfaction } \\
\text { with } \\
\text { Achievement }\end{array}$ & $\begin{array}{c}\text { Satisfaction } \\
\text { with Respect }\end{array}$ \\
\hline Ln(pay) & 0.047 & 0.517 & 0.053 & 0.008 \\
Rank & $(0.032)$ & $(0.039)$ & $(0.031)$ & $(0.032)$ \\
& 0.316 & 0.196 & 0.238 & 0.247 \\
\#Observations & $(0.048)$ & $(0.051)$ & $(0.048)$ & $(0.050)$ \\
Workplaces & & & & \\
Individuals & & & & \\
Log-L & 14703 & 14703 & 14703 & 14703 \\
Pseudo R & -18805.6 & -20219.5 & -18928.9 & -20336.0 \\
\hline
\end{tabular}

The other controls in the regression equations are as listed in Table 2 


\section{Table 6c}

Well-being Regression Equations with Pay and Range as Independent Variables

\begin{tabular}{l|rrrr}
\hline & $\begin{array}{c}\text { Satisfaction } \\
\text { with } \\
\text { Influence }\end{array}$ & $\begin{array}{c}\text { Satisfaction } \\
\text { with Pay }\end{array}$ & $\begin{array}{c}\text { Satisfaction } \\
\text { with } \\
\text { Achievement }\end{array}$ & $\begin{array}{c}\text { Satisfaction } \\
\text { with } \\
\text { Respect }\end{array}$ \\
\hline Ln(pay) & 0.081 & 0.516 & 0.075 & 0.044 \\
Range & $(0.031)$ & $(0.039)$ & $(0.031)$ & $(0.032)$ \\
& 0.198 & 0.191 & 0.161 & 0.127 \\
\#Observations & $(0.048)$ & $(0.054)$ & $(0.050)$ & $(0.050)$ \\
Workplaces & & & & \\
Individuals & & & & \\
Log-L & 14703 & 14703 & 14703 & 14703 \\
Pseudo R & -18821.0 & -20220.0 & -18936.7 & -20347.5 \\
\hline
\end{tabular}

The other controls in the regression equations are as listed in Table 2 


\section{Table 7a}

Well-being Regression Equations with Pay and Rank as Independent Variables (comparisons are within an occupational group)

(Standard errors are in parentheses)

\begin{tabular}{l|rrrr}
\hline & $\begin{array}{l}\text { Satisfaction } \\
\text { with } \\
\text { Influence }\end{array}$ & $\begin{array}{c}\text { Satisfaction } \\
\text { with Pay }\end{array}$ & $\begin{array}{c}\text { Satisfaction } \\
\text { with } \\
\text { Achievement }\end{array}$ & $\begin{array}{c}\text { Satisfaction } \\
\text { with Respect }\end{array}$ \\
\hline Ln(pay) & -0.033 & 0.306 & -0.036 & -0.027 \\
Rank & $(0.062)$ & $(0.076)$ & $(0.063)$ & $(0.073)$ \\
& 0.358 & 0.194 & 0.297 & 0.327 \\
\#Observations & $(0.078)$ & $(0.087)$ & $(0.081)$ & $(0.080)$ \\
Workplaces & & & & \\
Individuals & 366 & 366 & 366 & 366 \\
Log-L & 4249 & 4249 & 4249 & 4249 \\
Pseudo R & -5505.8 & -5784.3 & -5550.2 & -5869.7 \\
& 0.070 & 0.143 & 0.127 & 0.086 \\
\hline
\end{tabular}

The other controls in the regression equations are as listed in Table 2

\section{Table 7b}

Well-being Regression Equations with Pay and Range as Independent Variables (comparisons are within an occupational group)

\begin{tabular}{l|rrrr}
\multicolumn{5}{c}{ (Standard errors are in parentheses) } \\
\hline & $\begin{array}{c}\text { Satisfaction } \\
\text { with } \\
\text { Influence }\end{array}$ & $\begin{array}{c}\text { Satisfaction } \\
\text { with Pay }\end{array}$ & $\begin{array}{c}\text { Satisfaction } \\
\text { with } \\
\text { Achievement }\end{array}$ & $\begin{array}{c}\text { Satisfaction } \\
\text { with } \\
\text { Respect }\end{array}$ \\
\hline Ln(pay) & -0.020 & 0.348 & -0.071 & 0.010 \\
& $(0.061)$ & $(0.072)$ & $(0.062)$ & $(0.072)$ \\
Range & 0.304 & 0.092 & 0.346 & 0.227 \\
& $(0.071)$ & $(0.078)$ & $(0.072)$ & $(0.073)$ \\
\#Observations & & & & \\
Workplaces & 366 & 366 & 366 & 366 \\
Individuals & 4249 & 4249 & 4249 & 4249 \\
Log-L & -5507.0 & -5786.8 & -5544.7 & -5873.7 \\
Pseudo R ${ }^{2}$ & 0.069 & 0.142 & 0.130 & 0.084 \\
\hline \multicolumn{7}{l}{ The other controls in the regression equations are as listed in Table 2 }
\end{tabular}


Table 8

Investigation 3: Quits Analysis
Means and standard deviations

Variable

Quit rate

Mean weekly pay

Standard deviation in weekly pay

Skewness in weekly pay

Largest occupation group has private pension at workplace

Number of employees at the workplace

Trade union recognised at the workplace

Public-sector establishment

Fraction employees who are female

Fraction employees who are 20 or under

Fraction employees who are over 50 mean sd

$0.144 \quad 0.174$

$257.777 \quad 127.862$

$146.973 \quad 72.318$

$1.074 \quad 0.956$

$0.749 \quad 0.434$

$92.434 \quad 306.601$

$0.493 \quad 0.500$

$0.330 \quad 0.471$

$0.571 \quad 0.294$

$0.057 \quad 0.095$

$0.154 \quad 0.116$

\section{Notes}

Information on quits comes from the Main Management Interview in the WERS98 Cross-Section codebook. The questionnaire asked for the annual number of voluntary resignations. The data stem from face-to-face interviews with the senior person at the workplace with responsibility for employee relations. A self-completion Employee Profile Questionnaire (EPQ) was sent to the workplace in advance of each interview, to be used for the recording of workforce data that required the respondent to consult workplace records. In the analysis here, this number is normalized by dividing by employment size. The dependent variable in later regressions is thus termed the quit rate in the workplace.

Further details of the data set are available by consulting the following web address: www.niesr.ac.uk/research/WERS98/MAINQ/Epqname.pdf 
Table 9

Quits Regressions Equations

Public and Private-Sector Samples Combined

(Standard errors are in parentheses)

$\begin{array}{lll}\text { Eqn. } 1 & \text { Eqn. } 2 & \text { Eqn. } 3\end{array}$

Mean pay (£00s)

$\begin{array}{lll}-0.021 & -0.015 & -0.009\end{array}$

$\begin{array}{lll}(0.005) & (0.006) \quad(0.007)\end{array}$

Standard deviation of pay (£00s)

$\begin{array}{lll}-0.006 & -0.001 & -0.004\end{array}$

$\begin{array}{lll}(0.008) & (0.008) & (0.009)\end{array}$

Skewness in pay

$\begin{array}{lll}0.018 & 0.010 \quad 0.012\end{array}$

$\begin{array}{lll}(0.006) & (0.006) \quad(0.006)\end{array}$

Public sector

$-0.063-0.026$

$(0.014) \quad(0.016)$

Log of workplace size

$-0.006 \quad-0.001$

$(0.004) \quad(0.004)$

$-0.049$

Pension (largest occupation group)

$(0.019)$

Union recognised at workplace

$-0.031$

$(0.012)$

$-0.025$

(0.030)

0.247

Fraction workforce 20 or under

$(0.116)$

Fraction workforce 50 or over

$-0.130$

(0.040)

Region dummies (11)

Industry dummies (12)

No Yes Yes

No Yes Yes

R-squared

$\begin{array}{lll}0.069 & 0.263 \quad 0.313\end{array}$

$\mathrm{N}$

$888 \quad 888 \quad 862$

The dependent variable is the quit rate in the workplace. 
Table 10

Quits Equations

Private-sector Only

(Standard errors are in parentheses)

\begin{tabular}{|c|c|c|c|}
\hline & Eqn. 1 & Eqn. 2 & Eqn. 3 \\
\hline Mean pay (£00s) & $\begin{array}{r}-0.032 \\
(0.007)\end{array}$ & $\begin{array}{r}-0.014 \\
(0.008)\end{array}$ & $\begin{array}{r}-0.010 \\
(0.009)\end{array}$ \\
\hline Standard deviation pay ( $£ 00$ s) & $\begin{array}{r}0.009 \\
(0.011)\end{array}$ & $\begin{array}{r}-0.006 \\
(0.012)\end{array}$ & $\begin{array}{r}-0.009 \\
(0.013)\end{array}$ \\
\hline Skewness in pay & $\begin{array}{r}0.010 \\
(0.009)\end{array}$ & $\begin{array}{r}0.019 \\
(0.009)\end{array}$ & $\begin{array}{r}0.020 \\
(0.009)\end{array}$ \\
\hline Log workplace size & & $\begin{array}{r}-0.005 \\
(0.006)\end{array}$ & $\begin{array}{r}0.001 \\
(0.006)\end{array}$ \\
\hline Pension (largest occupation group) & & & $\begin{array}{l}-0.052 \\
(0.022)\end{array}$ \\
\hline Union recognised at workplace & & & $\begin{array}{r}-0.029 \\
(0.014)\end{array}$ \\
\hline Fraction workforce female & & & $\begin{array}{r}-0.067 \\
(0.040)\end{array}$ \\
\hline Fraction workforce 20 or under & & & $\begin{array}{r}0.264 \\
(0.133)\end{array}$ \\
\hline Fraction workforce 50 or over & & & $\begin{array}{c}-0.203 \\
(0.058)\end{array}$ \\
\hline Region dummies (11) & No & Yes & Yes \\
\hline Industry dummies (12) & No & Yes & Yes \\
\hline R-squared & 0.081 & 0.277 & 0.338 \\
\hline $\mathrm{N}$ & 570 & 570 & 549 \\
\hline
\end{tabular}

The dependent variable is the quit rate in the workplace. 


\section{Figure Captions}

Figure 1. Two hypothetical distributions to illustrate the predictions of rankdependence.

Figure 2. The six stimulus distributions used in Experiment 1.

Figure 3. Data (symbols) and fit of the range-frequency model (solid lines) for the six different distributions used in Experiment 1. Each data point represents the mean of 24 observations. 
(Figure 1)

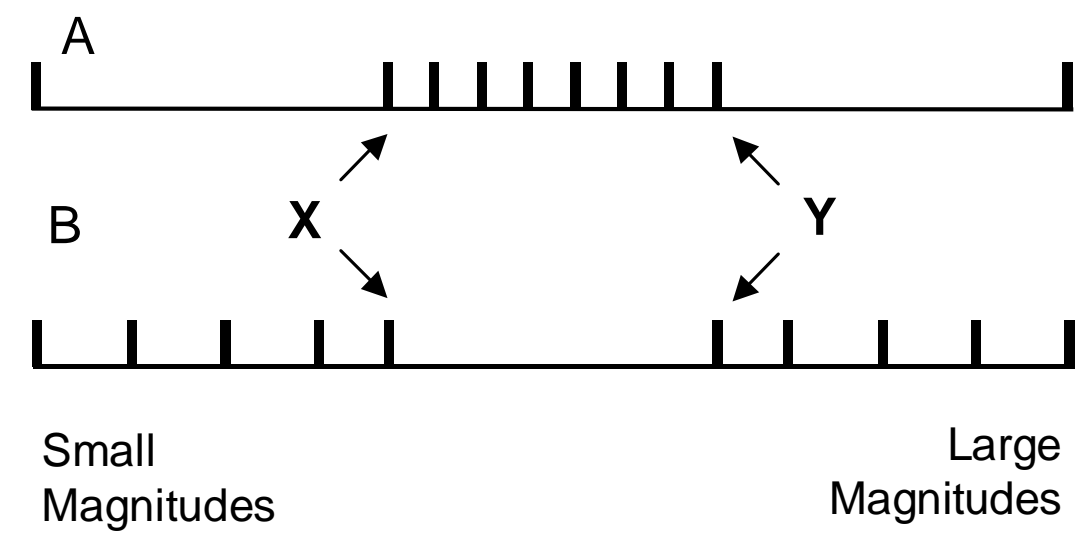


(Figure 2)

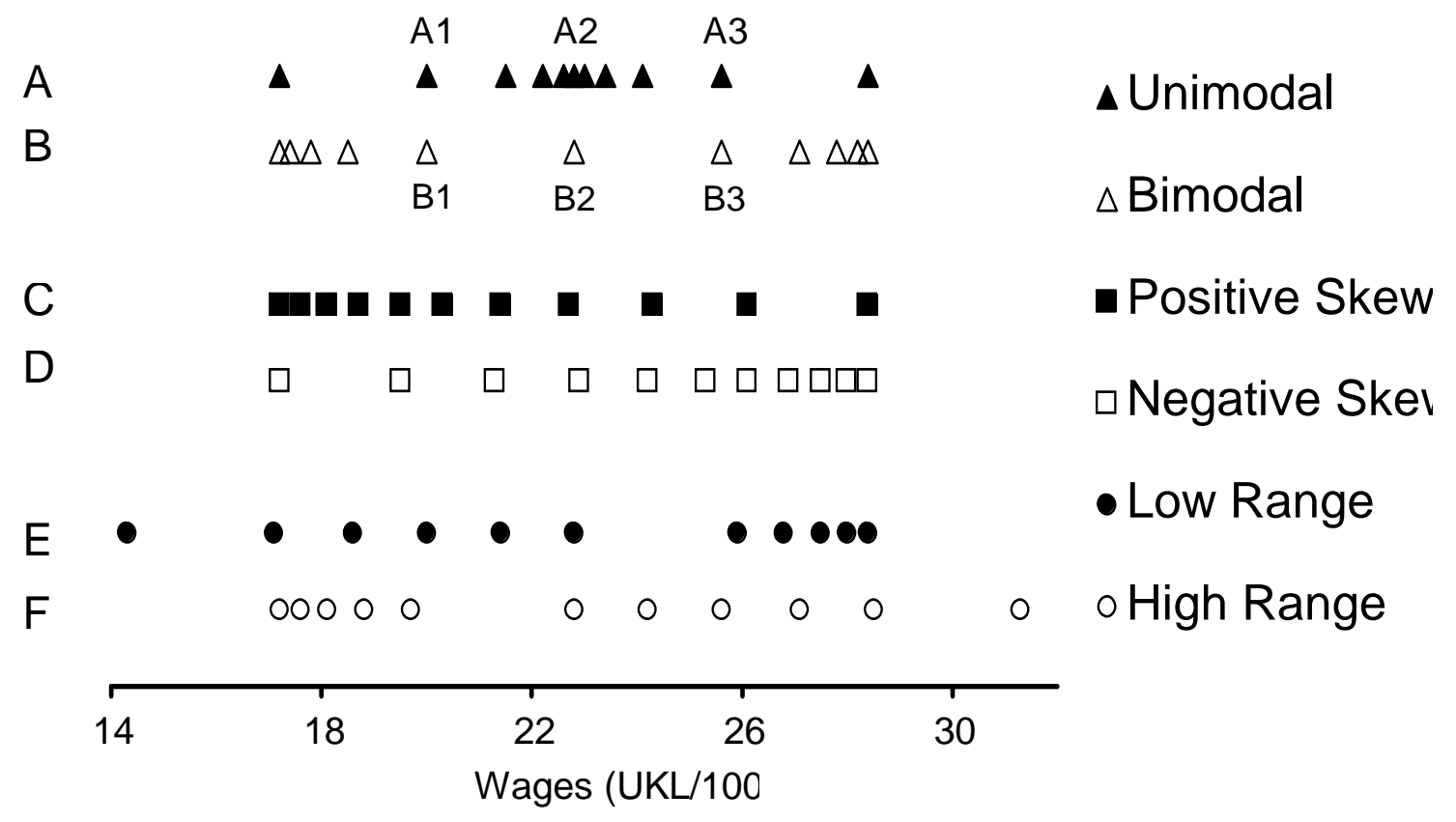


(Figure 3a)

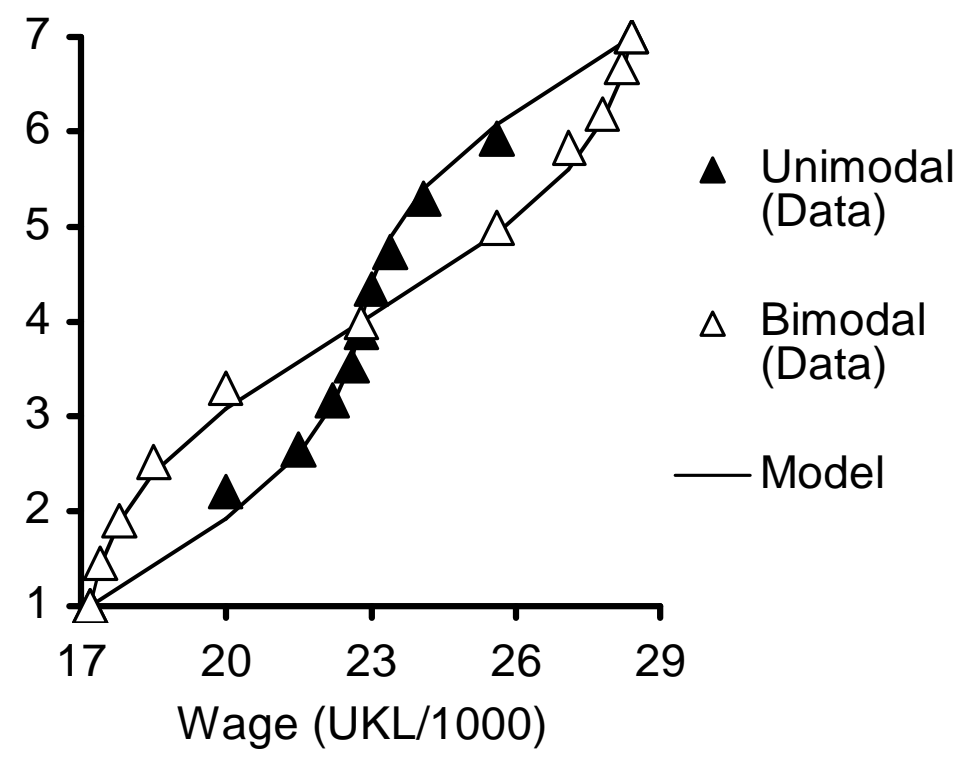


(Figure 3b)

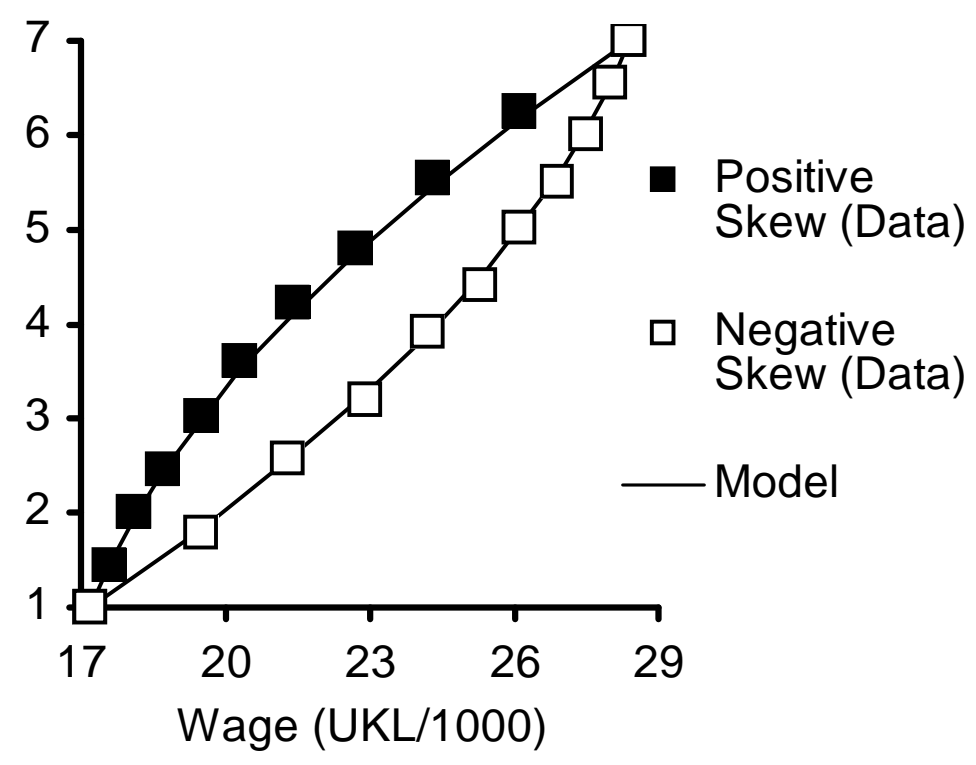


(Figure 3c)

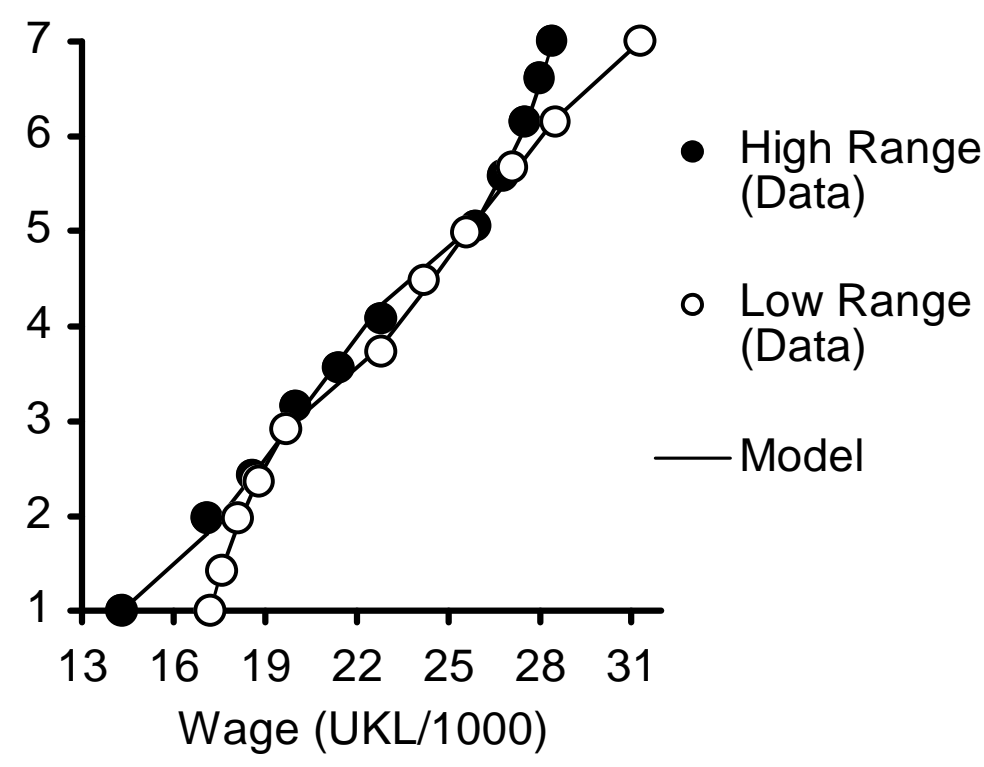

